\title{
Autophagy modulates temozolomide- induced cell death in alveolar Rhabdomyosarcoma cells
}

Adel Rezaei Moghadam', Simone C. da Silva Rosa ${ }^{1,7}$, Ehsan Samiei ${ }^{2,5}$, Javad Alizadeh 1,6, Jared Field ${ }^{1,7}$, Philip Kawalec ${ }^{1}$, James Thliveris ${ }^{1}$, Mohsen Akbari, ${ }^{2,5}$, Saeid Ghavami ${ }^{1,3,6}$ and Joseph W. Gordon (1) ${ }^{1,4,7}$

\begin{abstract}
Rhabdomyosarcoma (RMS) is a muscle-derived tumor. In both pre-clinical and clinical studies Temozolomide (TMZ) has been recently tested against RMS; however, the precise mechanism of action of TMZ in RMS remains unclear. Here we demonstrate that TMZ decreases the cell viability of the RH30 RMS and C2C12 cell line, where cells display evidence of mitochondrial outer membrane permeability. Interestingly, the C2C12 mouse myoblast line was relatively more resistant to TMZ-induced apoptosis. Moreover, we observed that TMZ activated biochemical and morphological markers of autophagy in both cell lines. Autophagy inhibition in both RH30 and C2C12 cells significantly increased TMZ-induced cell death. In RH30 cells, TMZ increased Mcl-1 and Bax protein expression compared to corresponding time match controls while in $\mathrm{C} 2 \mathrm{C} 12 \mathrm{Mcl}-1, \mathrm{BCl}-2, \mathrm{BCl}-\mathrm{XL}$, and Bax protein expression were not changed. Baf-A1 cotreatment with TMZ significantly decrease $M C l-1$ expression compared to TMZ while

increase Bax expression in $\mathrm{C} 2 \mathrm{C} 12$ cells (Bcl2 and Bcl-XL do not significantly change in Baf-A1/TMZ co-treatment). Using a three-dimensional (3D) $\mathrm{C} 2 \mathrm{C} 12$ and $\mathrm{RH} 30$ culture model we demonstrated that TMZ is significantly more toxic in $\mathrm{RH} 30$ cells (live/dead assay). Additionally, we have observed in our 3D culture model that TMZ induced both apoptosis (cleavage of PARP) and autophagy (LC3-puncta and localization of LC3/p62). Therefore, our data demonstrate that TMZ induces simultaneous autophagy and apoptosis in both RH30 and C2C12 cells in 2D and 3D culture model, where RH30 cells are more sensitive to TMZ-induced death. Furthermore, autophagy serves to protect RH30 cells from TMZ-induced death.
\end{abstract}

\section{Introduction}

Rhabdomyosarcoma (RMS) is an aggressive soft-tissue malignant tumor that occurs in both children and adults ${ }^{1}$, but comprises up to $50 \%$ of all childhood soft tissue sarcomas $^{2,3}$. Clinically, survival among patients with metastatic RMS has not improved appreciably in the past

\footnotetext{
Correspondence: Saeid Ghavami (saeid.ghavami@umanitoba.ca) or Joseph W. Gordon (joseph.gordon@umanitoba.ca)

'Department of Human Anatomy and Cell Science, Max Rady College of Medicine, Rady Faculty of Health Science, University of Manitoba, Winnipeg, Canada

${ }^{2}$ Laboratory for Innovations in Microengineering (LiME), Department of Mechanical Engineering, University of Victoria, Victoria, BC, Canada Full list of author information is available at the end of the article Edited by: I. Amelio
}

years, emphasizing an urgent need to develop new strategies to treat and prevent this disease $e^{4}$. Four subgroups of RMS have been described based on histological, genetic, and clinical criteria ${ }^{5}$ : embryonal RMS, pleomorphic RMS, spindle cell/sclerosing RMS, and alveolar RMS (ARMS). ARMS is an aggressive subtype of RMS suffered by adolescents and young adults ${ }^{5}$. In addition, the high-mortality rate in ARMS has been attributed to the presence of oncogenic fusion proteins (i.e., PAX3-FOXO1 and PAX7FOXO1) generated by chromosomal translocations ${ }^{6}$.

Recently, oral alkylating agents such as TMZ have received considerable attention in RMS pre-clinical and clinical studies ${ }^{7}$. TMZ has a broad spectrum of antitumor activity while being well-tolerated by the patient due to its

\section{(c) 2018 The Author(s).}

\footnotetext{
(c) (i) Open Access This article is licensed under a Creative Commons Attribution 4.0 International License, which permits use, sharing, adaptation, distribution and reproduction cc) in any medium or format, as long as you give appropriate credit to the original author(s) and the source, provide a link to the Creative Commons license, and indicate if changes were made. The images or other third party material in this article are included in the article's Creative Commons license, unless indicated otherwise in a credit line to the material. If material is not included in the article's Creative Commons license and your intended use is not permitted by statutory regulation or exceeds the permitted use, you will need to obtain permission directly from the copyright holder. To view a copy of this license, visit http://creativecommons.org/licenses/by/4.0/.
} 
relatively low toxicity ${ }^{8-10}$. The mechanism of action of TMZ results in the production of a highly reactive methyldiazonium cation ${ }^{11}$ that transfers its methyl group to purine bases of DNA resulting in double-stranded breaks during repair ${ }^{12-15}$. This process leads to G2/M cell cycle arrest and activation of apoptosis ${ }^{16-18}$. However, the cellular response to TMZ also involves alterations in gene expression that have been shown to be cancer-cell specific. Thus, the pathways involved in apoptosis induction may be different for each type of sarcoma, and there is little information regarding how TMZ affects ARMS at the cellular level. In our studies, we explored the role of autophagy in RH30 cells to further elucidate the mechanism of action of TMZ.

Autophagy is a conserved physiological process of cellular self-eating, which plays an essential role in cellular housekeeping activity by degrading protein aggregates, cytoplasmic components, and damaged or dysfunctional organelles. At least three distinct forms of autophagy can be activated depending on the route that cytoplasmic material is delivered to lysosomes, such as chaperonemediated autophagy, microautophagy, and macroautophagy (from here on referred to as autophagy) ${ }^{19-22}$. The role of autophagy in cancer cell biology is complicated and evolves throughout tumorigenesis. For instance, autophagy has been shown to promote cancer cell survival during conditions of a nutrient or hypoxic stress and contribute to cell demise through autophagic cell death (i.e., type II programmed cell death) ${ }^{23}$. More recently, autophagy has also been shown to contribute to epithelium to mesenchymal transition (EMT) and promote cancer metastasis in different cancer models ${ }^{21,24}$. In RH30 cells, autophagy is known to be a crucial process in the maintenance of cellular viability and proliferation ${ }^{25}$. Furthermore, inhibition of autophagy by the Atg7 knockdown, or pharmacological inhibition with chloroquine or Baf-A1 treatment, has been demonstrated to decrease cell growth and reduced viability in RMS cell lines ${ }^{26,27}$.

Autophagy and apoptosis are two independent processes, but under certain conditions, they cooperate in a hierarchical relationship to regulate the turnover of organelles and proteins within cells, and of cells within organisms $^{28,29}$. However, within a given cell, considerable cross-talk exists between apoptosis and autophagy, and nature of this cross-talk can change in a cell contextdependent manner ${ }^{30-32}$. Generally, autophagy is a rapidly induced survival pathway activated by sublethal stress, whereas apoptosis is initiated at lethal doses of stress ${ }^{30}$. However, in certain conditions, autophagy may also contribute to the induction of cell death by either the activation of programmed cell death type II, activation of mitochondrial-dependent cell death pathways (i.e. apoptosis or necrosis), or by providing substrates to promote ATP-dependent apoptotic mechanisms ${ }^{33-35}$. The BCL-2 family of proteins plays a crucial role in the regulation of the cross-talk between apoptosis and autophagy, consisting of both pro-survival and pro-death family members $^{36,37}$. However, the role of the BCL-2 family in regulating apoptosis and autophagy in ARMS is not well dissected.

In this report, we demonstrate that TMZ decreased cell viability of the RH30 RMS cell line and C2C12 cell line in presence of autophagy activation. TMZ induces outer mitochondrial membrane permeabilization without changes in mitochondrial membrane potential. We also show that treatment of $\mathrm{RH} 30$ and $\mathrm{C} 2 \mathrm{C} 12$ cells with low concentrations of the autophagy flux inhibitor Baf-A1, significantly increased TMZ-induced cell death. Collectively, these observations help define the role of autophagy in RH30 cells and contribute to our knowledge regarding the mechanism of action of TMZ in PAX3-FOXO1 positive sarcomas.

\section{Results \\ TMZ induces apoptotic cell death in $\mathrm{C} 2 \mathrm{C} 12$ and $\mathrm{RH} 30$ cell lines}

We treated both the RH30 RMS cell line and $\mathrm{C} 2 \mathrm{C} 12$ myoblasts with $\operatorname{TMZ}(0,50,100,250,500$, and $1000 \mu \mathrm{M}$ in 48,72 , and $96 \mathrm{~h}$ ) and cell viability was examined by MTT assay. TMZ-induced cell death in a dose- and timedependent manner in $\mathrm{C} 2 \mathrm{C} 12$ cells (Fig. 1a-c) and RH30 cells (Fig. 1d-f), where RH30 cells appeared more sensitive to the effects of TMZ. We confirmed that TMZ (100 $\mu \mathrm{M}, 72 \mathrm{~h}$ ) increases apoptotic cell death in both $\mathrm{C} 2 \mathrm{C} 12$ and RH30 cell lines using a propidium iodide (PI)dependent method (i.e. Nicoletti assay). Following TMZ treatment, the percentage of apoptotic cells was approximately three times more than control $\mathrm{C} 2 \mathrm{C} 12$ cells (Fig. 1g). However, in RH30 cells, TMZ-induced apoptosis by 17.5 times compared to the control cells (Fig. 1g). Therefore, TMZ significantly activated higher levels of apoptosis in RH30 cells than in C2C12 cells (Fig. 1h). We also performed flow cytometry analysis where cells were stained with Annexin-V and PI (Fig. 1i, j). In C2C12 cells treated with TMZ, we observed an increase in Annexin- $\mathrm{V}$ positive $(\mathrm{A}+/ \mathrm{P}-)$ cells, but no change in double positive cells $(\mathrm{A}+/ \mathrm{P}+)$. Interestingly, we also observed a decrease in PI positive cells (A-/P+) (Fig. 1i). Conversely, in RH30 cells treated with TMZ we observed significant increases in Annexin- $\mathrm{V}$ positive and double positive cells, with a corresponding decreased in double negative cells (A-/P -) (Fig. 1j). These observations are consistent with our MMT and Nicoletti findings, and suggest that RH30 cells are more sensitive to the apoptosis inducing effects of TMZ compared to $\mathrm{C} 2 \mathrm{C} 12$ cells.

To investigate the cellular mechanisms behind the differential response to TMZ treatment, we performed a series of experiments to evaluate intrinsic cell death 

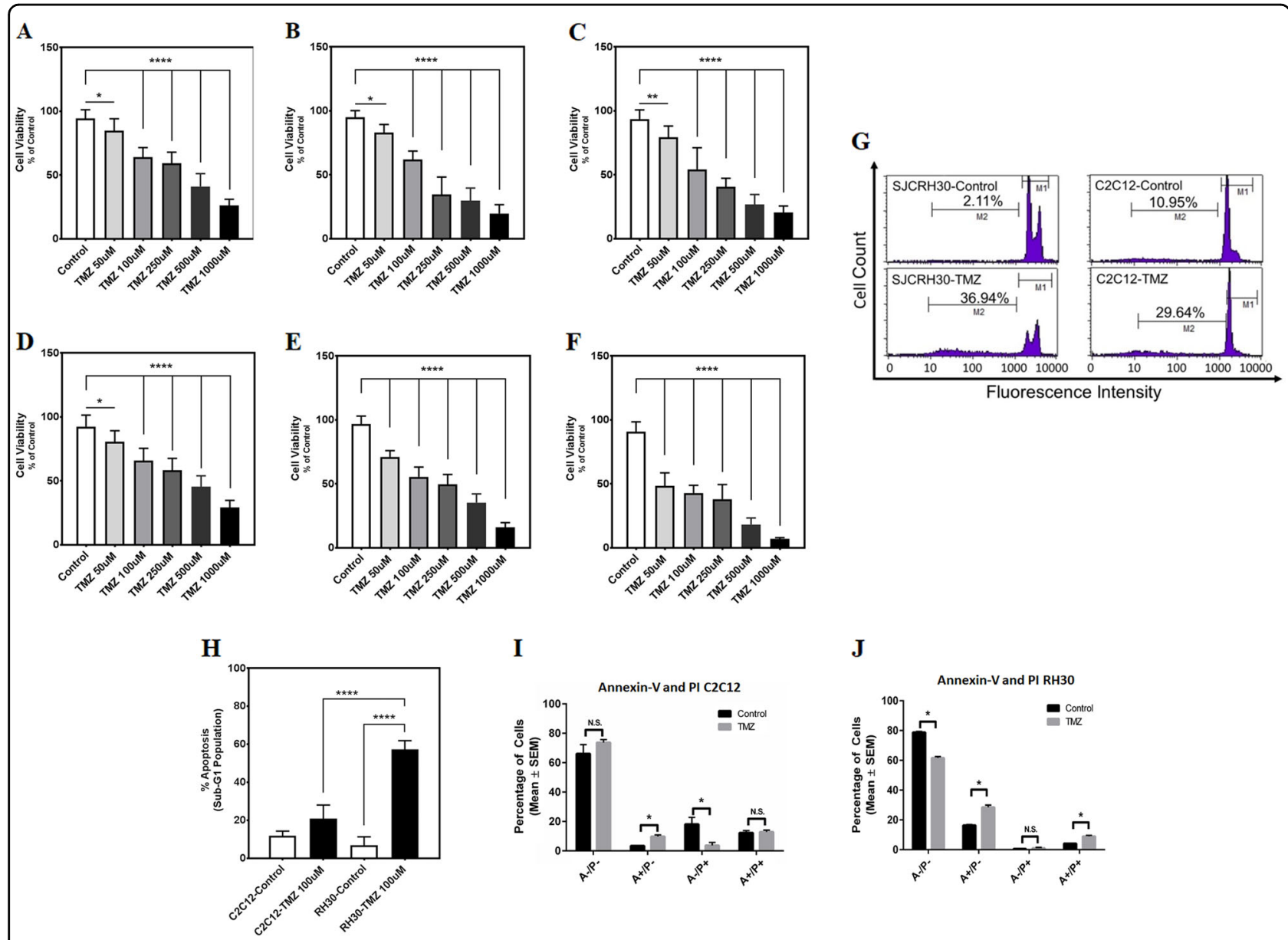

I
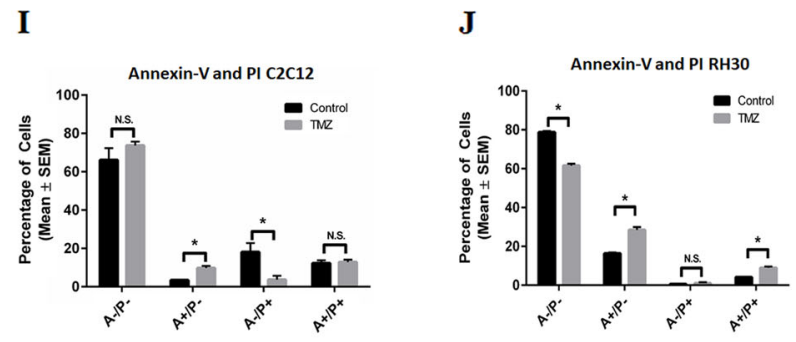

$\mathbf{K}$
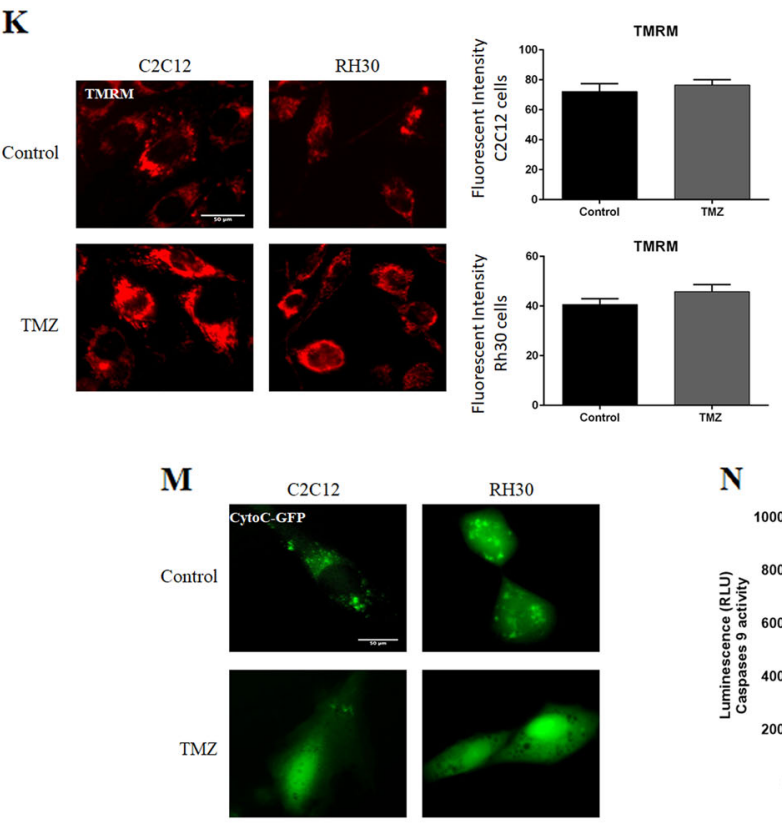

L
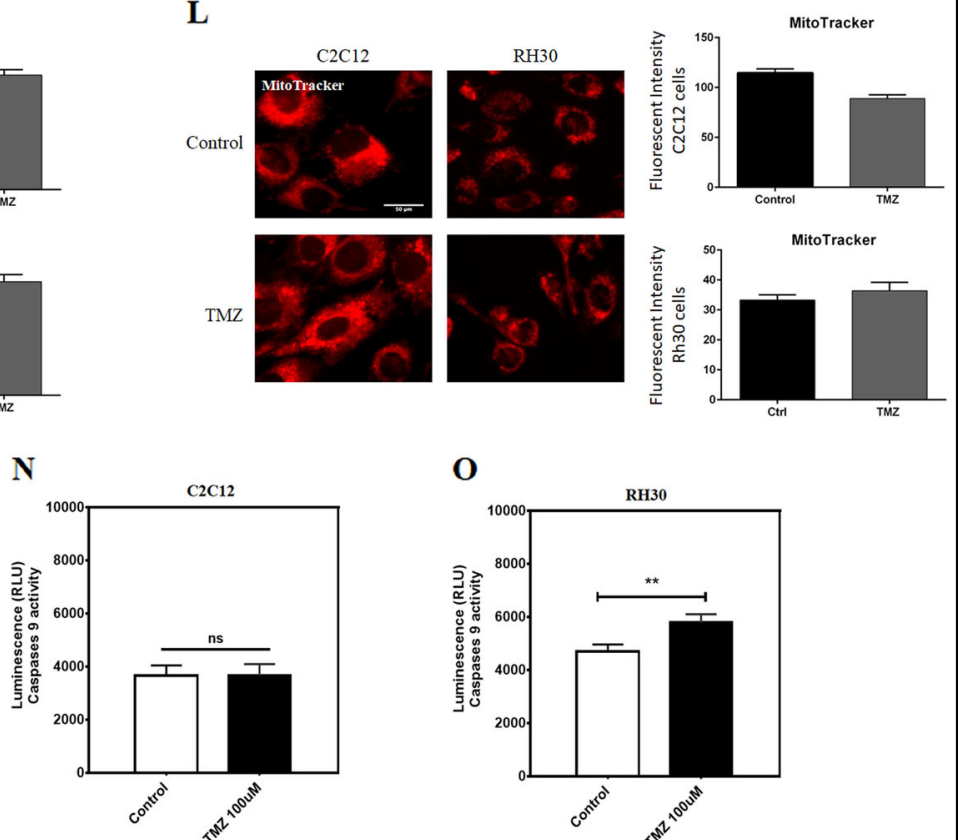

O

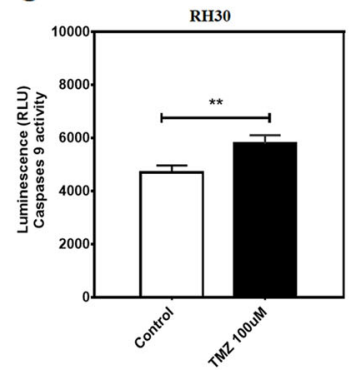

Fig. 1 (See legend on next page.) 
(see figure on previous page)

Fig. 1 TMZ induces apoptotic cell death in C2C12 and RH30 cell lines. a-c C2C12 cells were treated with TMZ (50, 100, 250, and 1000 $\mu$ M) and cell viability was assessed 48,72 , and $96 \mathrm{~h}$ after that by MTT assay. Control cells for each time point were treated with the solvent control (DMSO). Results are expressed as a percentage of corresponding time point control and represent the means \pm SD of 15 replicates in three independent experiments ( $\left.{ }^{*} P<0.01 ;{ }^{* * *} P<0.0001\right)$. d-f $C 2 C 12$ cells were treated TMZ $(50,100,250$, and $1000 \mu M)$ and cell viability was assessed 48,72 , and $96 \mathrm{~h}$ after that by MTT assay. Control cells for each time point were treated with the solvent control (DMSO). Results are expressed as a percentage of corresponding time point control and represent the means \pm SD of 15 replicates in three independent experiments $\left({ }^{* *} P<0.01 ;{ }^{* * * *} P<0.0001\right)$. g Representative figures of the flow cytometry histogram for C2C12 and RH30 are shown. Cells were treated with TMZ (100 $\mu \mathrm{M}, 72 \mathrm{~h}$ ) and Percent subG1 abundance induced by TMZ $(100 \mu \mathrm{M})$ or DMSO solvent control after $72 \mathrm{~h}$. The Sub-G1 population showed an abundance of apoptotic cell death in each treatment. $\mathbf{h}$ The average of the sub-G1 population of C2C12 and RH30 cells which were treated with TMZ (100 $\mu \mathrm{M}, 72 \mathrm{~h})$ and DMSO solvent control has been measured. Results represent the means \pm SD of six replicates in three independent experiments $(* * * *<<0.0001)$. i, $\mathbf{j} C 2 \mathrm{C} 12$ and RH30 cells were treated with TMZ and stained with Annexin-V-FITC (A) and PI (P) and analyzed by flow cytometry $(n=3)\left({ }^{*} P<0.05\right)$. $\mathbf{k}$ TMRM staining of

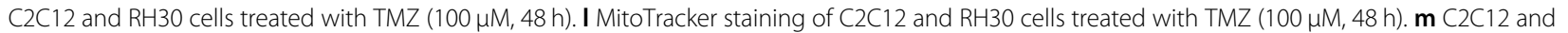
RH30 cells were transfected with cytochrome C-GFP (CytoC-GFP) and treated with TMZ $(100 \mu \mathrm{M}, 48 \mathrm{~h})\left({ }^{*} P<0.05\right)$. $\mathbf{n}, \mathbf{o}$ C2C12 and RH30 cells were treated with $100 \mu \mathrm{M}$ TMZ for $48 \mathrm{~h}$ and then Caspase-9 activity was measured using Caspase-Glo luminescence assay. $\left.{ }^{* *} P<0.01\right)$

pathways initiated by mitochondria. We stained cells with the mitochondrial membrane potential-sensitive dye $\mathrm{TMRM}^{38,39}$, as rapid dissipation of mitochondrial membrane potential has been recently associated with mitochondrial permeability transition. Surprisingly, we observed that TMZ treatment did not lead to mitochondrial depolarization at this dose and time in either cell line (Fig. 1k). No change in MitoTracker staining was observed in RH30 cells, indicating that mitochondrial content was not altered by TMZ treatment, however we did observe a modest, but significant reduction in MitoTracker staining in $\mathrm{C} 2 \mathrm{C} 12$ cells (Fig. 11). Next, we transfected cells with a cytochrome C-GFP fusion construct that has been previously shown to accumulate in the mitochondrial intermembrane space and be released into the cytosol during mitochondrial outer membrane permeabilization $(\mathrm{MOMP})^{40}$. Following transfection, we observed fluorescent mitochondrial puncta in both untreated cell lines (Fig. 1m). When RH30 and C2C12 cells were treated with TMZ, we observed release of cytochrome C-GFP into the cytosol. In RH30 cells, no fluorescent puncta remained following TMZ treatment; however, in $\mathrm{C} 2 \mathrm{C} 12$ cells residual puncta remained in up to $20 \%$ of cells (Fig. $1 \mathrm{~m}$ ). Collectively, these findings indicate that TMZ induces MOMP without mitochondrial permeability transition.

Caspase- 9 is an important effector of intrinsic or mitochondrial-regulated apoptosis ${ }^{41-44}$. It has been recently reported that TMZ induces caspase-dependent apoptosis in several cancer cells ${ }^{45,46}$. Thus, we determined the effects of TMZ-induced MOMP on caspase- 9 activation. Following treatment of TMZ $100 \mu \mathrm{M}$ for $48 \mathrm{~h}$ (Fig. 1n, o), we observed a significant activation of caspase-9 in RH30 cells ( $\left.{ }^{* *} P<0.01\right)$; however, the caspase-
9 activity was unchanged in $\mathrm{C} 2 \mathrm{C} 12 \mathrm{~s}$ at this dose and time $(P>0.05)$.

\section{TMZ induces autophagy activation in $\mathrm{C} 2 \mathrm{C} 12$ and $\mathrm{RH} 30$ cells}

Previous reports have shown that TMZ induces simultaneous apoptosis and autophagy in glioblastoma cells $^{22,47}$. Thus, we evaluated if differential activation of autophagy could explain the increased toxicity to TMZ in RH30 cells compared to $\mathrm{C} 2 \mathrm{C} 12$ cells. Our results demonstrate that TMZ induces autophagy in both $\mathrm{C} 2 \mathrm{C} 12$ and RH30 cell lines. Immunoblotting results showed lipidation of LC3B, Atg5-12 conjugation, and increase in Beclin-1 expression in both cell lines, indicating autophagy activation by TMZ $(100 \mu \mathrm{M})$ (Fig. 2a). In RH30 and $\mathrm{C} 2 \mathrm{C} 12$ cells, fluorescent microscopy confirmed that TMZ increased the number of LC3-GFP puncta and lysosomal activation (LysoTracker red fluorescence intensity), which co-localized in TMZ treated cells (Fig. 2b, c). Also, transmission electron microscopy (TEM) further confirmed autophagy activation in RH30 and $\mathrm{C} 2 \mathrm{C} 12$ cells (double membrane autophagosome formation), after $72 \mathrm{~h}$ treatment with TMZ (100 $\mu$ M) (Fig. 2d).

To investigate whether the accumulation of LC3B-II is due to an increase in autophagic flux or prevention of autophagic proteolysis, we used Baf-A1 $(100 \mathrm{nM})$ for different time points $(2,3,4 \mathrm{~h})$ to study autophagy flux. It has been previously shown that a high concentration of Baf-A1 with short time point exposures decreases lysosome numbers, causes fusion block, and suppresses autolysosome destruction by interfering with late-stage autophagosome-lysosome fusion ${ }^{19,48}$. As shown by western blot, treatment with Baf-A1 $(100 \mathrm{nM}) 2$, and $4 \mathrm{~h}$ markedly increased the accumulation levels of LC3-II and 


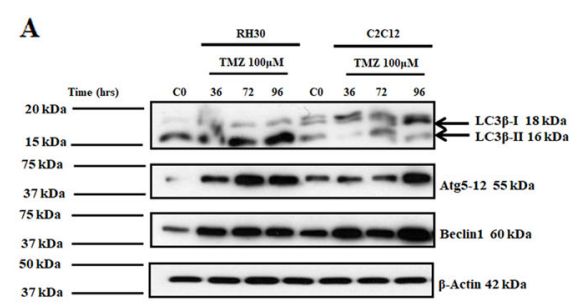

B
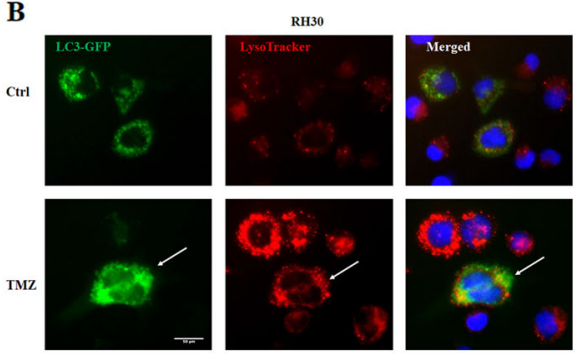

C
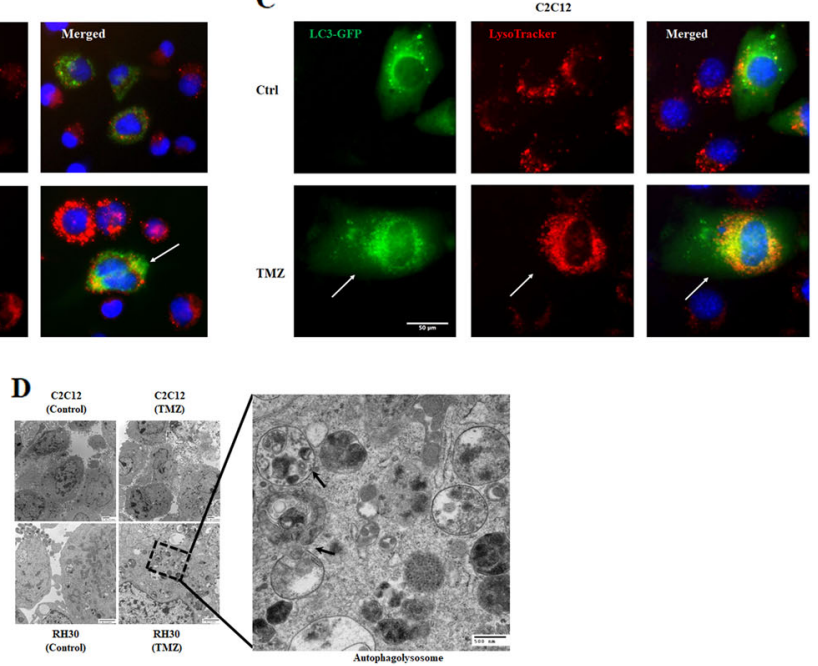

E

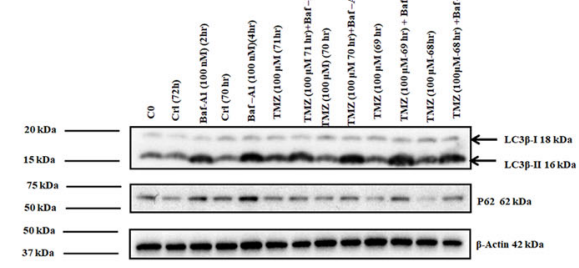

F

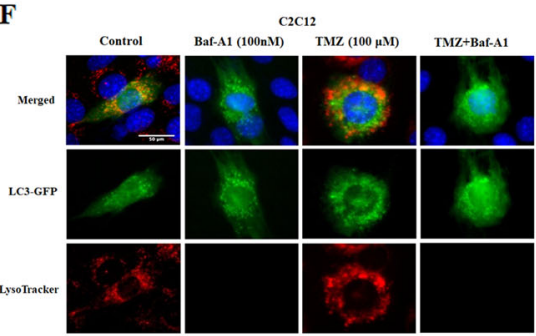

G
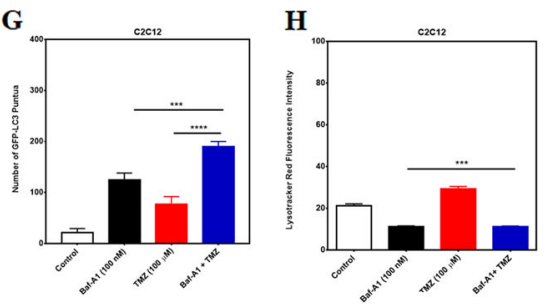

I
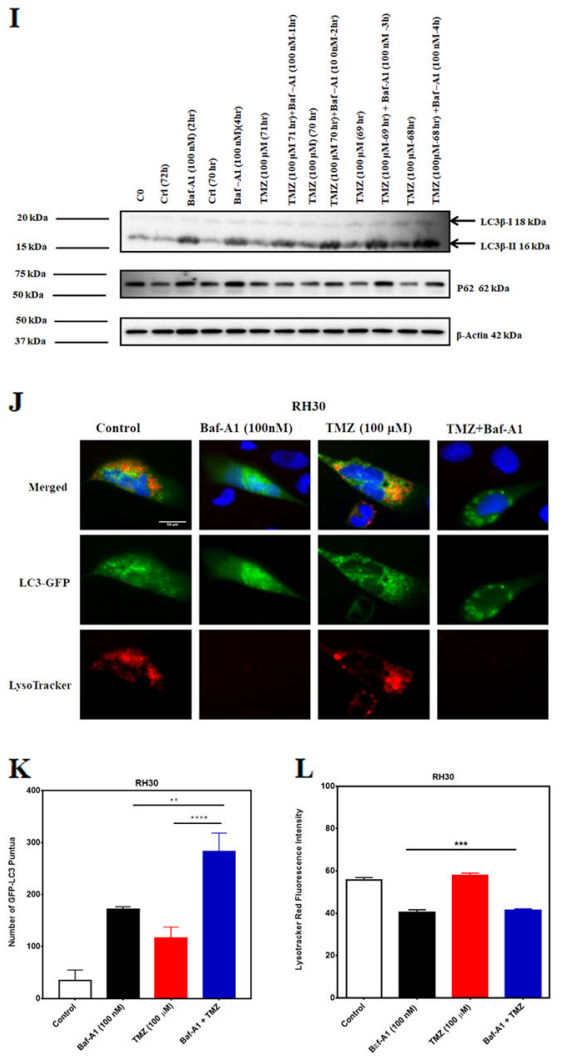

Fig. 2 (See legend on next page.) 


\begin{abstract}
(see figure on previous page)
Fig. 2 TMZ induces autophagy in C2C12 and RH30 cell lines. a C2C12 and RH30 cells were treated with TMZ (100 $\mu \mathrm{M}, 36,72,96 \mathrm{~h})$ and autophagy hallmark was detected in both $\mathrm{C} 2 \mathrm{C} 12$ and RH30 cell lines using immunoblotting. TMZ-induced LC3 3 lipidation, Atg5-12 conjugation, and Beclin-1 expression in both cell lines. Beta-actin was used as loading control. Data are representative of three independent experiments using different cultures. b, c RH30 and C2C12 cells were treated with TMZ (100 $\mu \mathrm{M}, 72 \mathrm{~h})$ and using immunocytochemistry LC3 puncta and changes in lysosomal activity (LysoTracker red staining) has been investigated. The results showed that TMZ increased LC3 puncta and LysoTracker red fluorescence intensity and co-localization of LC3 puncta and LysoTracker in both RH30 and C2C12 cells. $\mathbf{d}$ Transmission electron microscopy showed that in treated RH30 and $\mathrm{C} 2 \mathrm{C} 12$ cells there are accumulated autophagosome-like structures compared to control and normal cells after $72 \mathrm{~h}$ treatment. Arrows show the autophagolysosomes containing the cargo (magnification $\times 11,600)$. e C2C12 cells were treated with TMZ $(100 \mu \mathrm{M}, 72 \mathrm{~h}$ ) and then treated with Baf-A1 (100 nM, 1, 2, 3, 4 h) to evaluate for autophagy flux. TMZ + Baf-A1 treatment induces more lipidated LC $3 \beta$ and reduces the degradation of p62 in RH30 cells. Beta-actin was used as the loading control. Data are representative of three independent experiments. $\mathbf{f}$ C2C12 cells were treated with TMZ $(100 \mu \mathrm{M}, 72 \mathrm{~h})$ and Baf-A1 $(100 \mathrm{nM},+4 \mathrm{~h})$ followed by immunocytochemistry to evaluate LC3 puncta and changes in lysosomal activity (LysoTracker red staining). The results showed that TMZ increased LC3 puncta and LysoTracker red fluorescence intensity in C2C12 cells. On the other hand, Baf-A1 and TMZ + Baf-A1 significantly decreased the LysoTracker red fluorescence in the presence of an accumulation of LC3 puncta showing the inhibition of autophagy flux by Baf-A1. $\mathbf{g}, \mathbf{h}$ Representative figures of LC3 puncta and fluorescence intensity for LysoTracker in $\mathrm{C} 2 \mathrm{C} 12$ cells in the presence of TMZ, Baf-A1, and TMZ/Baf-A1 treatment. These results showed that the number of LC3 puncta is significantly higher in cells which are treated with Baf-A1 and TMZ + Baf-A1. However, the fluorescence intensity of LysoTracker was lower in Baf-A1, and TMZ + Baf-A1 treated cells. i RH30 cells were treated with TMZ (100 $\mu \mathrm{M}, 72 \mathrm{~h})$ and then treated with Baf-A1 $(100 \mathrm{nM}, 1,2,3,4 \mathrm{~h})$ to evaluate for autophagy flux. TMZ/ Baf-A1 treatment induces more $L C 3 \beta$ lipidation and reduces the degradation of p62 in RH30 cells compared to TMZ and Baf-A1 single treatment. Beta-actin was used as the loading control. Data are representative of three independent experiments. $\mathbf{j}$ RH30 cells were treated with TMZ (100 $\mu \mathrm{M}$, $72 \mathrm{~h}$ ) and Baf-A1 (100 nM, +4 h) followed by immunocytochemistry to evaluate LC3 puncta and changes in lysosomal activity (LysoTracker red staining). The results showed that TMZ increased LC3 puncta and LysoTracker fluorescence intensity in RH30 cells. On the other hand, Baf-A1 and TMZ + Baf-A1 significantly decreased the LysoTracker red fluorescence showing the inhibition of autophagy by Baf-A1. $\mathbf{k}$ I Representative figures of LC3 puncta and fluorescence intensity for LysoTracker in RH30 cells in the presence of TMZ, Baf-A1, and TMZ/Baf-A1 treatment. These results showed that many LC3 puncta are significantly higher in cells which are treated with Baf-A1 and TMZ + Baf-A1. However, the fluorescence intensity of LysoTracker was lower in Baf-A1, and TMZ + Baf-A1 treated cells
\end{abstract}

P62 in both $\mathrm{C} 2 \mathrm{C} 12$ and $\mathrm{RH} 30$ cells. Combination treatment of cells with TMZ $(100 \mu \mathrm{M}, 72 \mathrm{~h})$ and Baf-A1 (100 $\mathrm{nM})$ at $1,2,3$, and $4 \mathrm{~h}$ showed a time-dependent accumulation of LC3B-II compared to cells treated with BafA1 (100 nM) alone (C2C12 cells Fig. 2e; RH30 cellsFig. 2i). These results indicate that TMZ induces autophagy flux in both cell lines. Consistent results were obtained using GFP-LC3, where in cells treated with a combination of TMZ and Baf-A1 ( $3 \mathrm{~h}, 100 \mathrm{nM}$ ) we observed increased GFP-LC3 puncta, compared to cells treated with Baf-A1 $(100 \mathrm{nM})$ alone (C2C12 cells Fig. 2e; RH30 cells Fig. 2i). Lysosomal activity was found to be lower in cells after treatment with Baf-A1 $(100 \mathrm{nM})$ alone, as well in combination with TMZ $(100 \mu \mathrm{M}, 60 \mathrm{~h})$ compared to the control and TMZ alone group, confirming lysosomal acidification inhibition and blockage of the autophagy flux (C2C12 cells Fig. 2f-h; RH30 cells Fig. 2i-l). Moreover, we demonstrate that the number of autophagic $\mathrm{C} 2 \mathrm{C} 12$ cells is higher in cells treated with Baf-A1 with and without TMZ. However, the fluorescence intensity of LysoTracker was lower in Baf-A1 and in TMZ + Baf-A1 treated cells (C2C12 cells Fig. 2f-h; RH30 cells Fig. 2i-l). Overall, these findings suggest that TMZ induces autophagy flux in $\mathrm{C} 2 \mathrm{C} 12$ and $\mathrm{RH} 30$ cells.

\section{Autophagy inhibition increases TMZ-induced apoptosis in C2C12 and RH30}

Next, we examined the effect of chemical inhibition of autophagy on TMZ-induced apoptosis. Previously, we demonstrated that low dose concentrations of Baf-A1 inhibits autophagy, but cell toxicity can occur at higher doses $^{49,50}$. Therefore, we performed a cell viability assay (MTT) to establish the appropriate concentration of Baf-A1 to inhibit autophagy with the least cytotoxic effect on $\mathrm{C} 2 \mathrm{C} 12$ and $\mathrm{RH} 30$ cells. $\mathrm{C} 2 \mathrm{C} 12$ and $\mathrm{RH} 30$ cells were treated with different concentration of Baf-A1 (0.1-10 nM) for 48 and $72 \mathrm{~h}$. Our results revealed that Baf-A1 (4 and $6 \mathrm{nM}$ ) had low cytotoxicity at $72 \mathrm{~h}$ in both cell lines (Fig. 3a, b), thus we evaluated the effectiveness of these two Baf-A1 concentrations to inhibit autophagy. Cells were treated with Baf-A1 ( 4 and $6 \mathrm{nM}$ ) for 48 , and $72 \mathrm{~h}$ and autophagy markers (LC3 lipidation and P62 degradation/accumulation) were investigated in both cell lines using western blotting. We observed that Baf-A1 (4 and $6 \mathrm{nM}$ ) inhibits autophagy, determined by the accumulation of lipidated LC3B-II and P62 (Fig. 3c) in both $\mathrm{C} 2 \mathrm{C} 12$ and $\mathrm{RH} 30$ cells. Next, we confirmed the effect of Baf-A1 (4 and $6 \mathrm{nM}$ ) on autophagy markers in C2C12 and RH30 cells treated with TMZ $(100 \mu \mathrm{M} / \mathrm{ml}$; Fig. 3d, e). Finally, we evaluated apoptosis by flow cytometry analysis with PI staining in cells treated with TMZ $(100 \mu \mathrm{M})$ and Baf-A1 (4 nM) for $72 \mathrm{~h}$. Both TMZ and

Baf-A1 increased the apoptotic cell population compared to control; however, the percentage of apoptosis in cells treated with the combination of TMZ and BafA1 was greater than either TMZ or Baf-A1 alone (Fig. 3f-h). Collectively, these findings demonstrate that autophagy inhibition increases TMZ-induced apoptosis in both $\mathrm{C} 2 \mathrm{C} 12$ and $\mathrm{RH} 30$ cells. 


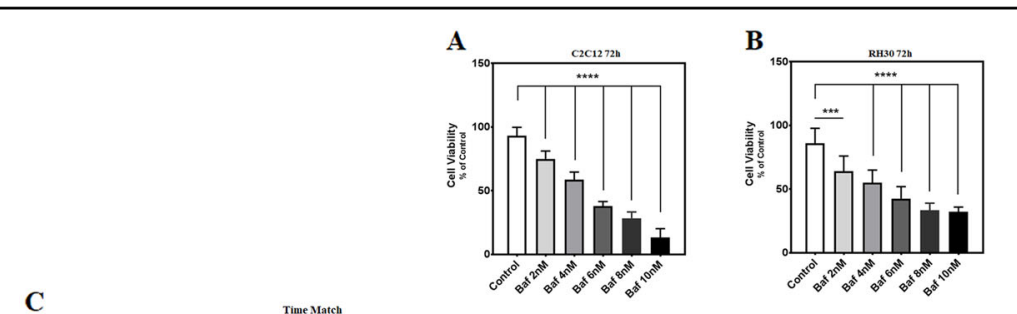

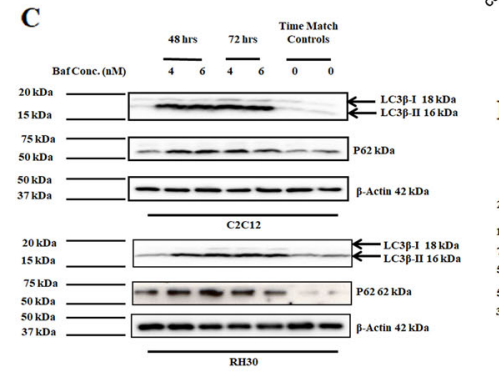

F

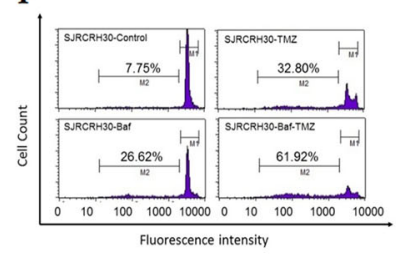

J

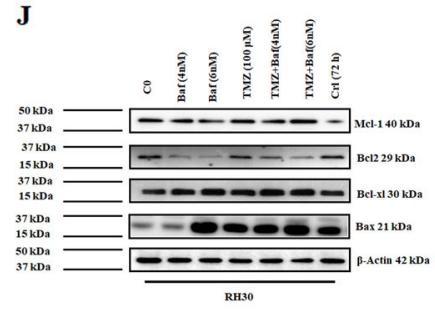

E

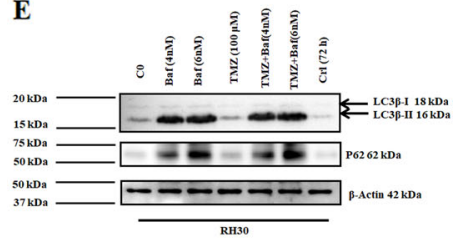

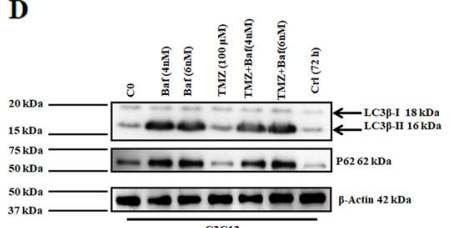

I
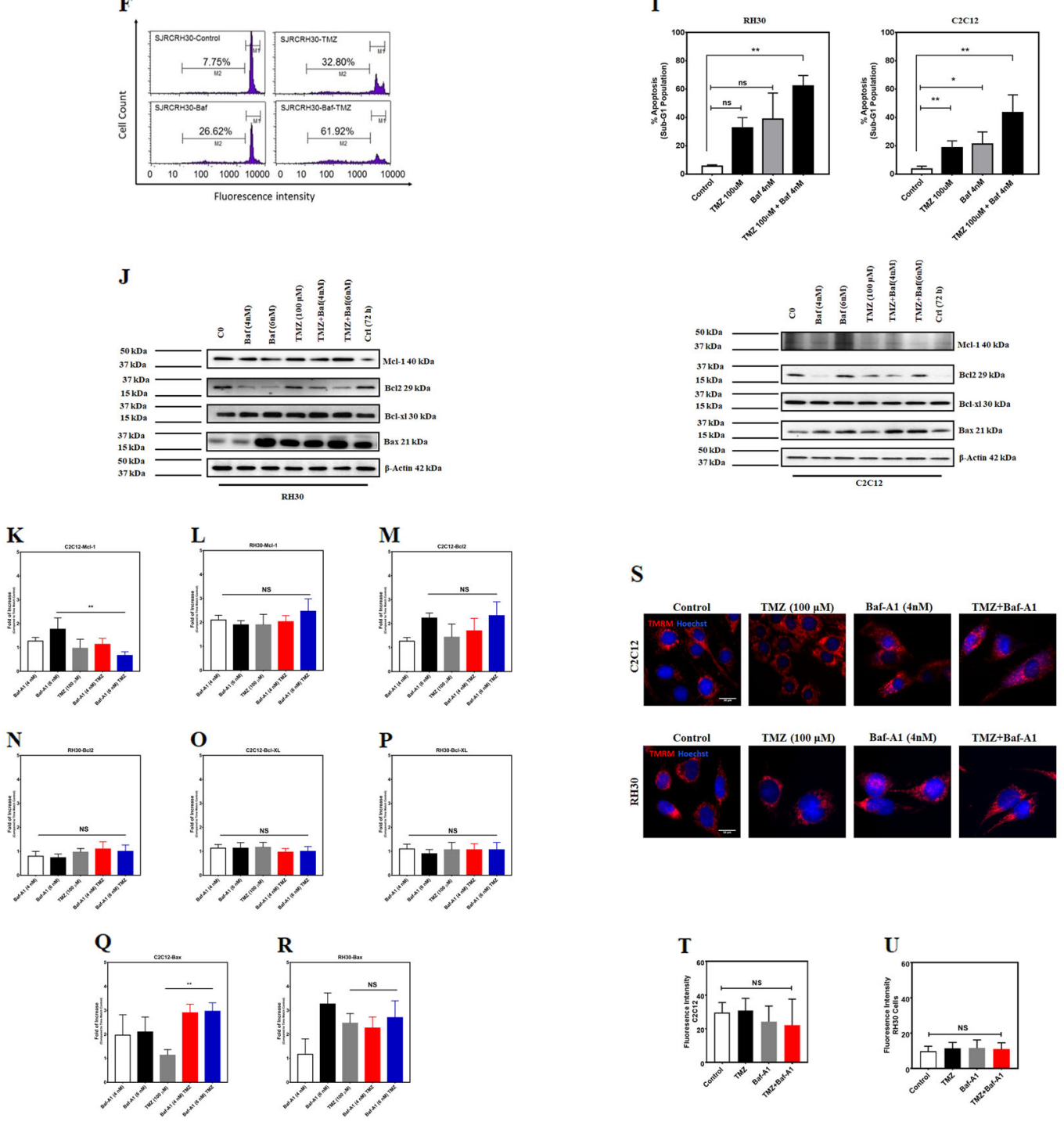

Fig. 3 (See legend on next page.) 
(see figure on previous page)

Fig. 3 Autophagy inhibition increases TMZ-induced apoptosis in $\mathbf{C} 2 \mathrm{C} 12$ and RH30 cells. $\mathbf{a}, \mathbf{b}$ C2C12 and RH30 cells were treated with Baf-A1 (2, $4,6,8$, and $10 \mathrm{nM}$ ) and cell viability was assessed after $72 \mathrm{~h}$ using MTT assay. Control cells for each time point were treated with the solvent control (DMSO). Results are expressed as a percentage of corresponding time point control and represent the means \pm SD of 15 replicates in three independent experiments $\left.{ }^{* *} \mathrm{P}<0.01{ }^{* * *} \mathrm{P}<0.0001\right)$. c $\mathrm{C} 2 \mathrm{C} 12$ and RH30 cells were treated with Baf- $\mathrm{A} 1(4$ and $6 \mathrm{nM}, 48,72 \mathrm{~h})$ and autophagy hallmark proteins were detected in both $\mathrm{C} 2 \mathrm{C} 12$ and $\mathrm{RH} 30$ cell lines using immunoblotting. Baf-A1 induces accumulation of lipidated LC3 $\beta$ and decreases the degradation of p62 in both cell lines. Beta-actin was used as loading control. Data are representative of three independent experiments using

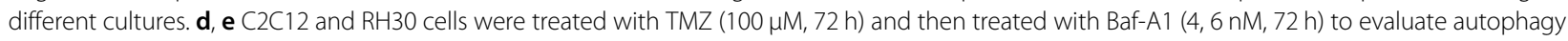
inhibition in the presence of Baf-A1 treatment. TMZ + Baf-A1 treatment induces LC3 $\beta$ lipidation and reduces the degradation of p62 in C2C12 and RH30 cells. Beta-actin was used as the loading control. Data are representative of three independent experiments. $\mathbf{f}-\mathbf{h}$ Representative figures of the flow cytometry histogram for RH30 are shown. Cells were treated with TMZ (100 $\mu \mathrm{M}, 72 \mathrm{~h})$, Baf-A1 (4 nM, $72 \mathrm{~h})$ and Baf-A1/TMZ. Percentage of sub-G1 abundance induced by TMZ (100 $\mu \mathrm{M}, 72 \mathrm{~h})$, Baf-A1 $(4 \mathrm{nM}, 72 \mathrm{~h})$ and Baf-A1/TMZ after $72 \mathrm{~h}$ has been showed. The Sub-G1 population showed an abundance of apoptotic cell death in each treatment. $\mathbf{g}, \mathbf{h ~ C 2 C 1 2}$ and RH30 cells were treated with TMZ (100 $\mu \mathrm{M}, 72 \mathrm{~h})$ and Baf-A1 (4 nM, 72 h) and then cell lysates were collected to examine the effect of TMZ, Baf-A1, and TMZ/Baf-A treatment on expression of Bcl2 family proteins (BCl-2, BCl-XL, MCl-1, and Bax). $\mathbf{k}-\mathbf{r}, \mathbf{k}, \mathbf{I}$ TMZ does not significantly change MCl-1 expression in both $\mathrm{C} 2 \mathrm{C} 12$ and RH30 cells. It is notable that Baf-A1 (6 nM)/TMZ COtreatment significantly $(P<0.01)$ decrease $\mathrm{Mcl}-1$ expression in $\mathrm{C} 2 \mathrm{C} 12$ cells while does not have any effect in RH30 cells. $\mathbf{m}, \mathbf{n}$ TMZ does not significantly change $\mathrm{BCl}-2$ expression in both $\mathrm{C} 2 \mathrm{C} 12$ and $\mathrm{RH} 30$ cells. TMZ/Baf-A combination treatment also does not significantly change $\mathrm{BCl}-\mathrm{XL}$ expression in both $\mathrm{C} 2 \mathrm{C} 12$ and $\mathrm{RH} 30$ cells. o, p TMZ does not significantly change Bcl-XL expression in both C2C12 and RH30 cells. TMZ/Baf-A combination treatment also does not significantly change Bcl-2 expression in both $\mathrm{C} 2 \mathrm{C} 12$ and $\mathrm{RH} 30$ cells. q, $\mathbf{r}$ TMZ does not significantly change Bax expression in both $\mathrm{C} 2 \mathrm{C} 12$ and RH30 cells. TMZ/Baf-A combination treatment significantly increase Bax-expression in $\mathrm{C} 2 \mathrm{C} 12$ cells $(P<0.01)$ while does not have a significant effect on its expression in RH30 cells. $\mathbf{s}-\mathbf{u}$ We have evaluated changes in mitochondrial membrane potential in the presence of

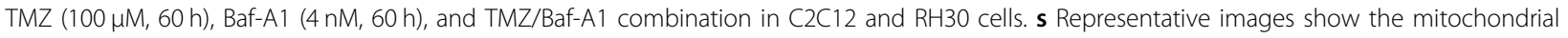
membrane potential measured by TMRM. Red color denotes TMRM staining. $\mathbf{t}$, $\mathbf{u}$ Measurement of the mean of TMRM fluorescence intensity shows

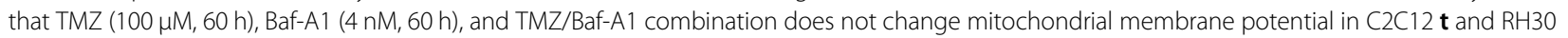
$\mathbf{u}$ cells. The data are representative of the mean fluorescence in at least 100 cells in each cell type. The data were analyzed by Student's $t$-test or ANOVA, followed by post hoc analysis. If $p<0.05$, results were considered statistically significant

To further dissect the mechanisms by which TMZ-induces apoptosis in presence of autophagy inhibition, we evaluated the expression of Bcl2 family proteins by western blot in $\mathrm{RH} 30$ and $\mathrm{C} 2 \mathrm{C} 12$ cells treated with TMZ and/or Baf-A1, as previously described ${ }^{31,35-37}$. We evaluated Bcl-2, Bcl-xl, Mcl-1 (anti-apoptotic), and Bax (pro-apoptotic). As shown in Fig. 3i, j, Baf-A1 (6 nM) cotreatment with TMZ $(100 \mu \mathrm{M})$ significantly decreased Mcl-1 expression $(P<0.01)$ compared to TMZ $(100 \mu \mathrm{M})$ with increased Bax expression $(P<0.01)$ in $\mathrm{C} 2 \mathrm{C} 12$ cells. $\mathrm{Bcl}-2$ and Bcl-XL did not significantly change in Baf-A1/ TMZ co-treatment (Figure K, M, N, and Q). Interestingly, we did not see any significant changes in RH30 cells with regards to levels of Mcl-1, Bcl-2, Bcl-XL, or Bax expression after co-treatment of Baf-A1/TMZ (Fig. 3l, n, p, r). We also evaluated the effect of TMZ $(100 \mu \mathrm{M}, 60 \mathrm{~h})$ and autophagy inhibition (Baf-A1, 4nM, $60 \mathrm{~h}$ ) on mitochondrial membrane potential in $\mathrm{C} 2 \mathrm{C} 12$ and $\mathrm{RH} 30$ cells. Interestingly, the results showed that TMZ, Baf-A1, and TMZ/Baf-A co-treatment do not affect mitochondrial membrane potential in either $\mathrm{C} 2 \mathrm{C} 12$ and $\mathrm{RH} 30$ cells (Fig. 3s-u).

\section{TMZ induces apoptosis and autophagy in $\mathrm{C} 2 \mathrm{C} 12$ and $\mathrm{RH} 30$ 3D culture}

Three-dimensional (3D) cellular models have been extensively used to mimic the 3D microenvironment of cells and to study the effects of extracellular matrix as a barrier against drug diffusion ${ }^{51,52}$. We used 3D models of $\mathrm{C} 2 \mathrm{C} 12$ and $\mathrm{RH} 30$ made of cell collagen disks (diameter =
$5 \mathrm{~mm}$ and thickness $=1 \mathrm{~mm} \mu \mathrm{m}$ ) to evaluate the effect of TMZ. These disks were fabricated by mixing $\mathrm{C} 2 \mathrm{C} 12$ and RH30 cells with collagen type $I(3 \mathrm{mg} / \mathrm{mL})$ at a final density of $2 \times 10^{6}$ cells $/ \mathrm{mL}$ and casting the disks in polydimethylsiloxane (PDMS) molds. After $24 \mathrm{~h}$, cells were treated with TMZ $(0-500 \mu \mathrm{M})$ for 48 and $96 \mathrm{~h}$. Cell viability was evaluated by staining cells with green-fluorescent calcein-AM (live) and red-fluorescent ethidium homodimer-1 (dead) dyes (Fig. 4c, d). Our results showed a significant decrease in the number of live cells in TMZ-treated groups in both $\mathrm{C} 2 \mathrm{C} 12$ and $\mathrm{RH} 30$ cells $(P<0.001)$, while TMZ induces more significant cell death in RH30 cells (Fig. 4e, f). Bright field images revealed significant changes in cell morphology of TMZ treated cells compared to control group in both $\mathrm{C} 2 \mathrm{C} 12$ (Fig. 4a) and RH30 cells (Fig. 4b). Additionally, TMZ treatment also induced higher PARP cleavage compared to control in both $\mathrm{C} 2 \mathrm{C} 12$ (Fig. 4g) and $\mathrm{RH} 30$ cells (Fig. 4h). Labeling of $\mathrm{C} 2 \mathrm{C} 12$ and $\mathrm{RH} 30$ cells by using autophagy markers demonstrated an increase in the number of autophagosomes in TMZ-treated groups as compared to corresponding time match controls (Fig. 4i, j).

\section{Discussion}

In the present study, we demonstrate that TMZ differentially induces apoptotic cell death in C2C12 and RH30 cells in both 2D and 3D culture models, and that the cell death is negatively regulated by autophagy. Interestingly, TMZ treatment does not change mitochondrial 


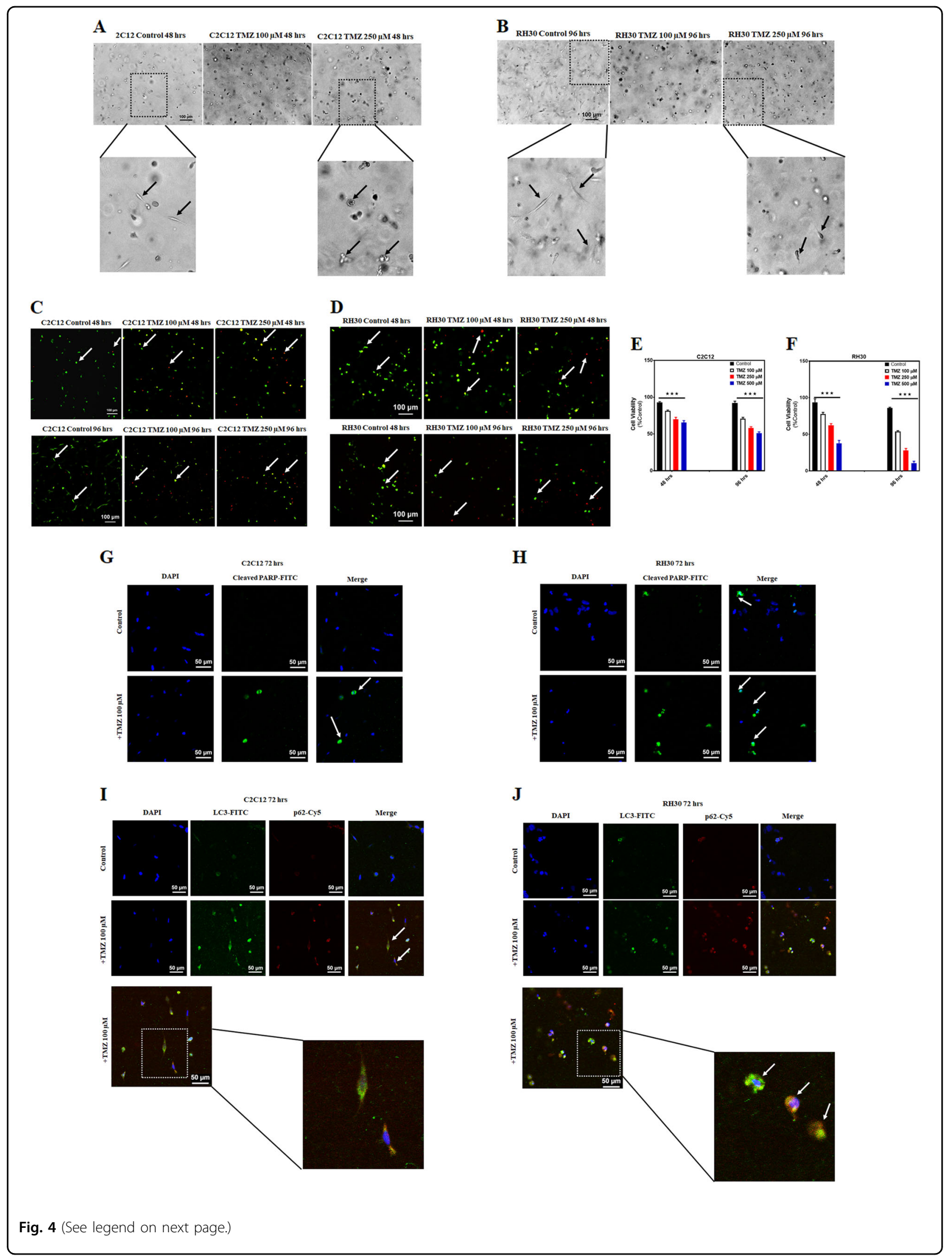


(see figure on previous page)

Fig. 4 TMZ induces apoptosis and autophagy in C2C12 and RH30 3D culture. $\mathbf{a}$, b Bright field image of $\mathrm{C} 2 \mathrm{C} 12 \mathbf{a}$ and RH30 b 3D culture which shows the morphology of untreated and TMZ treated cells $(100,250 \mu \mathrm{M}, 4 \mathrm{~h})$ in 3D culture. c-f Viability assay was done by adding the live/dead solution to cells 48 and $96 \mathrm{~h}$ after treatment with TMZ $(0-500 \mu \mathrm{M})$. Cells were incubated for $2 \mathrm{~h}$ in the dark at room temperature, rinsed twice with DPBS, and confocal microscopy was used to capture live/dead cell images in C2C12 c and RH30 d cells. e, $\mathbf{f}$ Quantification of live/dead assay was measured by calculating the ratio of live: total cells which showed a significant decrease in viability of $\mathrm{C} 2 \mathrm{C} 12$ e and RH $30 \mathbf{f}$ cells treated with different concentrations of TMZ. The data showed TMZ significantly induces cell death in both $\mathrm{C} 2 \mathrm{C} 12$ and RH30 cells $(P<0.001)$ while TMZ induces more cell death in RH30 compared to C2C12 cells. $\mathbf{g}$, $\mathbf{h}$ IF labeling of $\mathrm{C} 2 \mathrm{C} 12$ cells $\mathbf{g}$ and RH30 cells $\mathbf{h}$ by cleaved PARP following treatment with TMZ (100 $\mu$ M, $72 \mathrm{~h}$ ) increased number of cells with cleaved PARP in TMZ treated cells in comparison to control cells which is the hallmark of increase of apoptosis in these cells. $\mathbf{i}, \mathbf{j}$ After treatment of C2C12 i and RH30 $\mathbf{j}$ cells with TMZ (100 $\mu \mathrm{M}, 72 \mathrm{~h})$, cells were IF labeled with autophagosome markers, LC3 and P62. Data showed that TMZ increases LC3 puncta (green) which is localized with p62 compared to corresponding time match control, a hallmark of autophagy induction in $\mathrm{C} 2 \mathrm{C} 12$ and $\mathrm{RH} 30$ 3D culture

membrane potential in either $\mathrm{RH} 30$ or $\mathrm{C} 2 \mathrm{C} 12$ cells, and the

differential TMZ-induced apoptosis in $\mathrm{C} 2 \mathrm{C} 12$ and RH30 cells cannot be entirely explained by changes in Bcl-2 anti-apoptotic (Bcl-2, Bcl-XL, and $\mathrm{Mcl}-1)$ and/or pro-apoptotic (Bax) protein expression.

There are currently a few therapeutic options available for patients with metastatic $\mathrm{RMS}^{53}$. To improve the therapeutic effect of chemotherapy in RMS, TMZ has recently received considerable interest as a factor for combination therapy because it is a well-tolerated oral alkylating agent with a broad spectrum of antitumor activity and relatively low toxicity ${ }^{12,13}$. Several Phase I trials suggest that using TMZ alone or in combination with other drugs is well tolerated in RMS when used in relapse settings ${ }^{54}$. The combination of irinotecan and TMZ, for instance, has shown synergistic antitumor activity against $\mathrm{RMS}^{54-57}$. Several studies have pointed out that autophagy acts as a pro-survival pathway which allows cancer cells to survive the existing stressed present in the tumor microenvironment ${ }^{23,58,59}$, such as the stresses caused by anticancer agents ${ }^{60}$. It has been found that autophagy and apoptosis have multiple direct and indirect interactions with each other ${ }^{31,61,62}$. In the present study, we observed that inhibition of autophagy could enhance the apoptotic effect of TMZ in C2C12 and RH30 cells; therefore, autophagy is a negative regulator of TMZinduced apoptosis in both $\mathrm{C} 2 \mathrm{C} 12$ and $\mathrm{RH} 30$ cells.

We have also determined that TMZ can activate apoptosis in a time and dose-dependent manner in RH30 cells. The enhancement of apoptosis was found to be associated with higher expression of histone $\mathrm{H} 2 \mathrm{~A}$ variant H2AX (data not shown). The phosphorylation of histone $\mathrm{H} 2 \mathrm{~A}$ variant $\mathrm{H} 2 \mathrm{AX}$ at Ser139 is a marker of DNA doublestrand breaks, a type of DNA damage that can lead to cell death, if unrepaired ${ }^{63,64}$. This mechanism of TMZinduced apoptosis has been validated in previous studies in other cancer cell lines which is consistent with our results ${ }^{1,65-67}$. Our results demonstrated that intrinsic or mitochondrial pathway is involved in the induction of apoptosis after TMZ treatment in RH30 cells (significant increase in caspase-9 activation) while TMZ-induced apoptosis is not caspase- 9 dependent in $\mathrm{C} 2 \mathrm{C} 12$ cells. It has been reported that TMZ-induced apoptosis is caspase dependent in different models, including glioma cells ${ }^{68-}$ 70 , and human glioma stem cells ${ }^{71}$. It has been previously reported that TMZ induces endoplasmic reticulum (ER)stress with subsequent unfolded protein response in many cell models. We are currently investigating whether differences in the ER-stress response or the extrinsic apoptosis pathway underlies the differential responsiveness of C2C12 and RH30 cells to TMZ treatment ${ }^{22,72}$.

Mitochondrial Bcl-2 family proteins are considered to be one of the critical components in the regulation of apoptotic cell death ${ }^{73-75}$ and known to be essential for the apoptotic response in chemotherapy, emphasizing that these proteins are potential therapeutic targets ${ }^{76,77}$. Interestingly our results showed that TMZ-induced apoptosis is not associated with changes in Bcl-2, Bcl-XL, Mcl-1, and Bax expression in RH30 and C2C12 cell lines. It has been previously reported that TMZ-induced apoptosis decreases mitochondrial membrane potential in glioma cell line $\mathrm{e}^{78,79}$ while our results showed that TMZ-induced apoptosis had not affected the mitochondrial membrane potential in both RH30 and C2C12 cells. This observation can be explained by our finding that TMZ has not affected the expression of antiapoptotic (Bcl-2, Bcl-XL, and Mcl-1), and pro-apoptotic (Bax) Bcl-2 family proteins. In addition, our data show that inhibition of autophagy by using Bafilomycin-A1 increased TMZ-induced apoptosis in RH30 and C2C12 cell lines without affecting mitochondrial membrane potential in these cells

This pilot study has expanded our understanding of the cross-talk between apoptosis and autophagy controlling TMZ-induced apoptosis. It has been shown that the maintenance of cellular viability in RH30 cells is dependent on baseline autophagy ${ }^{25}$, while loss of ATG7 or BafA1 treatment can negatively regulate proliferation of RH30 cells ${ }^{26,27}$. We found that Baf-A1 inhibited baseline autophagy in $\mathrm{RH} 30$ and $\mathrm{C} 2 \mathrm{C} 12$ cells and decreased their viability. More importantly, our study showed that the 
combination treatment of RH30 cells with Baf-A1 and TMZ has a synergic effect on TMZ-induced apoptosis compared to treatment with either TMZ or Baf-A1 alone. This suggests that autophagy has a survival role in RH30 and C2C12 cells treated with TMZ and the autophagy inhibitor enhances the antitumor effect of TMZ against RH30 cells by activation of apoptosis.

We have reproduced two-dimensional (2D) RH30 and $\mathrm{C} 2 \mathrm{C} 12$ culture results in a $3 \mathrm{D}$ culture models (Fig. 4) which showed that TMZ induces higher apoptotic cell death in RH30 cells in the presence of autophagy activation in both cell models. These discoveries are an essential step for translational application towards developing new therapies for RMS. The findings in most cellbased assays are demonstrated in monolayer or suspension culture models, which may give false negative or positive results due to an artificial cellular environment. It also represents restricted significance for in vivo studies and often little value in foreseeing clinical effectiveness of both generally cytotoxic and molecularly targeted drugs ${ }^{80}$. $3 \mathrm{D}$ cultures have received more attention and become more accepted in the last few years as an essential strategic toolkit for developing new cancer therapy ${ }^{80,81}$. Furthermore, 3D in vitro culture systems mimic different aspects of human tumor tissue environment, therefore should be considered as an advanced model for routine anti-tumor drug testing ${ }^{80}$. In our current findings, we confirmed that 3D RMS culture can be used to dissect the role of TMZ in RMS therapy.

Our findings revealed that autophagy is a negative regulator of TMZ-induced apoptosis in both RH30 and $\mathrm{C} 2 \mathrm{C} 12$ cells. In addition, we have shown that TMZinduces MOMP and apoptosis that is not readily explained by changes in Bcl-2, Bcl-XL, Mcl-1, or Bax expression, and is not accompanied by changes in mitochondrial membrane potential.

\section{Materials and methods \\ Drugs and reagents}

Antibodies against human p62 (5114, 1:1000), Bax (5023, 1:1000), Bcl-2 (3498, 1:1000), Bcl-xl (2762,1:1000) Mcl-1 (94296, 1:1000) Bak (12105, 1:1000) Nix (12396, 1:1000) Beclin-1(3495, 1:1000), SQSTM1/p62 (D5L7G) (88588, 1:100 for ICC), LC3B (D11) XP ${ }^{\oplus}$ (3868, 1:100 for ICC), Cleaved PARP (Asp214) (D64E10) XP ${ }^{\circledR}$ (5625, 1:100 for ICC), and Bid (2002, 1:1000) were purchased from Cell Signaling Technology (Beverly, MA, USA); LC3 was purchased from Sigma-Aldrich (St. Louis, MO, USA); glyceraldehyde-3-phosphate-dehydrogenase (GAPDH) and Actin were purchased from Santa Cruz Biotechnology, Inc. (Dallas, TX, USA). Anti-rabbit IgG (whole molecule) and anti-mouse IgG (Fab specific) peroxidaseconjugated secondary antibodies were purchased from
Sigma-Aldrich (St. Louis, MO, USA). Autophagy inhibitor Bafilomycin-A1 (Baf-A1), rabbit anti-human/mouse/rat LC3 (L8918, 1:3,000), anti-mouse IgG (A8924, 1:3000), Temozolomide, anti-rabbit IgG (A6154, 1:5000), propidium iodide (PI), and 3-(4,5-dimethyl-2-thiazolyl)-2,5diphenyl-2H-tetrazolium bromide) (MTT) were purchased from Sigma-Aldrich Canada Co, Oakville, CA. Caspase-Glo ${ }_{-}-9$ assay was purchased from Promega (Toronto, ON, Canada). Enhanced chemiluminescence (ECL) prime regents (western blotting detection reagent) were purchased from Amersham-Pharmacia Biotech. Hyperfilm $^{\text {Tx }}$ ECL was purchased from Fisher Scientific. Polydimethylsiloxane (PDMS) was purchased from Dow Corning $^{{ }^{\mathrm{m} x}}, 5 \mathrm{~mm}$ diameter sterile biopsy punches were purchased from Stevens Company, $5 \mathrm{mg} / \mathrm{mL}$ bovine collagen type 1 with neutralized $\mathrm{pH}$ was purchased from Advanced BioMatrix. Penicillin-streptomycin (Pen-Strep, 10,000 units $/ \mathrm{mL}$ penicillin and $10,000 \mu \mathrm{g} / \mathrm{mL}$ streptomycin) was purchased from Gibco $^{\circledR}$, fetal bovine serum (FBS) was purchased from Millipore Sigma. Secondary antibodies with conjugated fluorescence (Alexa Fluor ${ }^{\circledR} 488$ AffiniPure Donkey Anti-Rabbit IgG, and Alexa Fluor ${ }^{\circledR} 647$ AffiniPure Donkey Anti-Mouse IgG) were purchased the from Jackson ImmunoResearch Inc. DAPI (4',6-Diamidino-2-Phenylindole, Dihydrochloride) was purchased from Thermo Fisher Scientific. IgG-free bovine serum albumin (BSA) was purchased from Jackson ImmunoResearch Inc. Live/dead viability kit was purchased from Millipore Sigma; formaldehyde $37 \%$ solution was purchased from VWR, Triton X-100 was purchased from Bio Basic Canada Inc. pCytochrome C-GFP was a gift from Douglas Green (Addgene plasmid \# 41182) ${ }^{40}$.

\section{Cell lines and cell culture}

Cell culture plastic ware, penicillin, and streptomycin were purchased from VWR (Toronto, ON, Canada). Cells were cultured in Roswell Park Memorial Institute (RPMI1640) with L-glutamine and $25 \mathrm{mM}$ HEPES (BioWhittaker; Cat \#: 12-115Q) and Dulbecco's Modified Eagle's Medium (DMEM) (CORNING; Cat \#: 50-003-PB) with $10 \%$ fetal bovine serum (FBS) (Gibco ${ }^{\text {tw }}$; Cat \#: 16000044). The human rhabdomyosarcoma cell line (RH30) [RC13, RMS 13, SJRH30] (ATCC ${ }^{\circledR}$ CRL $\neg 2061^{\text {tx }}$ ) (Human muscle cancer cells) and mouse muscle cell line (C2C12) (ATCC ${ }^{\oplus}$ CRL $\left.\neg 1772^{\mathrm{mw}}\right)$ were used in this project. RH30 cell lines were cultured in (RPMI-1640) with L-glutamine and 25 $\mathrm{mM}$ HEPES media, and $\mathrm{C} 2 \mathrm{C} 12$ cells were cultured in (DMEM) with high glucose media. Both media were supplemented with FBS (10\%), penicillin (1\%), and streptomycin (1\%). Cells were grown to $35-40 \%$ confluency on a $100 \mathrm{~mm}$ cell culture plate, 6-well plates, and 96-well plates. Cells were maintained in a humidified incubator with $95 \%$ air and $5 \% \mathrm{CO}_{2}$ at $37^{\circ} \mathrm{C}$ and were passaged once every $2-3$ days. 


\section{Cell viability assay}

The RH30 cells $(30,000$ cells $/ \mathrm{ml})$ and C2C12 (20,000 cells $/ \mathrm{ml}$ ) were seeded in 96-well plates and treated with different concentrations of TMZ in different time points $(0-1000 \mu \mathrm{M}, 0-96 \mathrm{~h})$. Cells were also treated with various concentrations $(0.1,1,2.5,5$, or $10 \mathrm{nM})$ of Baf-A1, an autophagy inhibitor, and cell viability was assessed after 48 and $72 \mathrm{~h}$. In each time point, $20 \mu \mathrm{l}$ of MTT 3-(4,5-dimethylthiazol-2-yl)-2,5-diphenyltetrazolium bromide $(5 \mathrm{mg} / \mathrm{ml})$, is the aqueous solubility of the reduced formazan product, was added into each well and incubated for $3 \mathrm{~h}$. Then, media gently were removed from each well using pipette and $200 \mu \mathrm{l}$ of solvent control (DMSO) was added to each well and mixed very well by pipetting to solubilize the MTT formazan. The plates were analyzed at a test wavelength of $570 \mathrm{~nm}$ on a plate reader, following a $20 \mathrm{~min}$ incubation at room temperature $(\mathrm{RT})^{82}$.

\section{Immunoblotting}

Western blot analysis was used to assess markers of apoptosis and autophagy in $\mathrm{RH} 30$ and $\mathrm{C} 2 \mathrm{C} 12$ cells. We examined hallmarks of intrinsic or extrinsic apoptotic pathway and autophagy signaling pathways, while GAPDH or actin was used to normalize the results. After treatment, cells were collected, and protein extracts were made using NP-40 lysis buffer (20 mM Tris- $\mathrm{HCl}$ (pH 7.5), $0.5 \%$ Nonidet P-40, 0.5 mM PMSF, $100 \mu \mathrm{M} \beta$-glycerol 3phosphate and $0.5 \%$ protease inhibitor cocktail). The extracts were kept in $-20^{\circ} \mathrm{C}$ until all extracts from different time points were collected. Samples were then sonicated in five times/five cycles using ultrasound sonicator, followed by centrifugation at $13,000 \times g$ for $10 \mathrm{~min}$ to collect the supernatant protein. Protein content was then determined via a Lowry protein assay, and protein samples were made. Prepared samples, of a volume between 15 and $20 \mu \mathrm{l}$, were heated at $90^{\circ} \mathrm{C}$ for $5 \mathrm{~min}$ before loading into $10-15 \%$ polyacrylamide gels (depending on the molecular weight of the proteins). Additionally, $10 \mu \mathrm{l}$ of a standard molecular weight marker (Thermo Fischer Scientific, ON, Canada) was loaded on each gel, as an approximate indicator of molecular protein weights. Proteins were immediately transferred under reducing conditions in transfer buffer $(500 \mathrm{nM}$ glycine, $50 \mathrm{mM}$ Tris- $\mathrm{HCl}$, and $20 \%$ methanol) to Immuno-Blot PVDF Membranes (Bio-Rad; \#1620177), at RT and 100 volts for 2-2.5 h. Upon transferring completion, membranes were carefully transferred into $5 \%$ non-fat dried milk in $1 \mathrm{X}$ Tris-buffered saline containing Tween (TBS/0.025\% tween 20; TBST) and placed on the shaker in the cold room overnight or RT for $2 \mathrm{~h}$. Following blocking, membranes were incubated with the proper dilution of primary antibodies in 1\% milk made in $1 \mathrm{X}$ TBST and kept in cold room $\left(4^{\circ} \mathrm{C}\right)$ overnight. Membranes were washed three times with 1X TBST $(0.025 \%$ Tween $)$ for $20 \mathrm{~min}$, and membranes were incubated with secondary antibodies (HRP) for $2 \mathrm{~h}$ on the shaker at RT. Membranes were rewashed three times for $20 \mathrm{~min}$ and incubated with enhanced chemiluminescence (ECL) reagents (Amersham-Pharmacia Biotech) for 2-3 min. Autoradiography visualized the signals. Obtained protein bands were evaluated for changes in the autophagy and apoptosis signaling pathways. To assess even protein loading, membranes were incubated in milk $1 \%$ with primary antibodies against GAPDH or Actin overnight, washed three times and probed with a secondary antibody to visualize the signals. In the instances of re-probing of other proteins on the same membrane, blots were incubated with stripping solution containing $200 \mathrm{nM}$ glycine, pH 2.5, 0.005 Tween 20 for $15 \mathrm{~min}$ at RT and followed the same instruction as after blocking for these blots ${ }^{83,84}$.

\section{Measurement of apoptosis by flow cytometry}

Apoptotic cells were assessed by flow cytometry with propidium iodide (PI), using the Nicoletti method ${ }^{85,86}$. RH30 and C2C12 cells were treated with TMZ $(100 \mu \mathrm{M}$, $72 \mathrm{~h}$ ) in cells cultured in 12-well plates. In each time point cells were detached by EDTA buffer and centrifuged at $1500 \times g$ for $5 \mathrm{~min}$ at $4{ }^{\circ} \mathrm{C}$. Then, cells were washed by PBS once. The cells were permeabilized and treated with a fluorescent dye that stains DNA quantitatively, using hypotonic PI lysis buffer $(0.1 \%$ Triton X-100, $1 \%$ sodium citrate, $0.5 \mathrm{mg} / \mathrm{ml}$ RNase A, $40 \mu \mathrm{g} / \mathrm{ml}$ propidium iodide). Before flow cytometry analysis, cells were incubated for at least $1 \mathrm{~h}$, at $4{ }^{\circ} \mathrm{C}$, and in the dark to prevent photobleaching. The measurement was in red fluorescence $(460 \mathrm{~nm})$ for 10,000 cells. Flow cytometer was adequately calibrated to gate out debris accurately. Finally, after elimination of residual debris, the percentage of normal and apoptotic nuclei were estimated by analysis of the DNA histogram ${ }^{86,87}$. The nuclei of apoptotic cells were located on the left side of the G1 peak. Apoptotic nuclei have less DNA compared to nuclei of healthy G0/G1cells, causing an increase in sub-G1 section in the fluorescence histogram which can be applied to distinguish apoptotic cells in samples. In each sample, the sub-G1 peak was measured and statistically compared with other samples ${ }^{86}$. Annexin-V FITC and PI staining was performed according to manufacturer's instructions (BD Biosciences 556547). Stained cells were analyzed on a Thermo Scientific Attune NxT flow cytometer with a $488 \mathrm{~nm}$ laser.

\section{Live cell imaging: LC3-GFP}

GFP-LC3 is a specific marker for the occurrence of autophagosomes formation ${ }^{88,89}$. GFP-LC3 is the fusion of the green fluorescent protein (GFP) and LC3 and can behave similarly as endogenous LC3 ${ }^{90,91}$. The GFP-LC3 is localized on the autophagosome membrane, and green 
punctate signals are observed ${ }^{91}$. To confirm TMZ-induced autophagy and autophagy flux inhibition through Baf-A1 $(100 \mathrm{nM})$, cells were transfected with a green fluorescent protein plasmid called LC3-GFP (Addgene, \#24920), a vector to visualize autophagosome formation in real time. $\mathrm{C} 2 \mathrm{C} 12 \mathrm{~s}$ were transfected using JetPrime Polyplus reagent, while RH30 cell line was transfected using Qiagen's Effectene reagent, as per manufacturer's instructions. After $48 \mathrm{~h}$ of transfection, cells were treated with TMZ $(60 \mathrm{~h})$ and Baf-A1 ( $3 \mathrm{~h}$ before imaging). LysoTracker red staining (Molecular Probes ${ }^{\mathrm{Tw}}$; LysoTracker ${ }^{\circledR}$ Red DND-99; L7528) was used to detect lysosomal activity and MitoTracker Red CMXRos at a concentration of $50 \mathrm{nM}$ to detect active mitochondrial membrane potential. Cells were stained for $30 \mathrm{~min}$ in $37^{\circ}$ $\mathrm{C}$ incubator. Using this approach, instances, where LC3GFP puncta co-localized with LysotTracker, were considered to be autophagic, while LC3-GFP co-localization with MitoTracker was interpreted as mitophagy ${ }^{21}$.

\section{Immunocytochemistry}

For detection of autophagy flux, we used immunocytochemistry (ICC) in C2C12 and RH30 cells ${ }^{31}$. Briefly, RH30 cells were cultured on coverslips in 6-well plates in RPMI media with $10 \%$ FBS. The cells were then treated with TMZ $(100 \mu \mathrm{M})$ or vehicle control and for $72 \mathrm{~h}$. Four hours before time point Baf-A1 $(100 \mathrm{nM})$ was added which already has been treated with TMZ. At the indicated time point, ICC was performed using the protocol described previously (Lysosomes were stained with LysoTracker red (Molecular Probes; $100 \mathrm{nM}, 10 \mathrm{~min}$ ) before fixation and permeabilization) ${ }^{31,92}$. GFP-LC3 punctuate co-localized with activated LysoTracker redd were identified as autophagic cells ${ }^{92}$.

\section{TMRM staining for mitochondrial membrane potential measurement}

Healthy mitochondrial membranes hold the electrical potential difference between the exterior and interior of the cell, well known as membrane potential. This is an important process, which is linked to a multitude of mitochondrial function. Tetramethylrhodamine methyl ester (TMRM), a cell-permeant dye, can accumulate inside the healthy and active mitochondria with intact membrane potential which then becomes fluorescent ${ }^{93,94}$. TMRM fluorescent signal disappears when there is a loss of mitochondrial membrane potential. TMRM fluorescence can be detected with fluorescence microscopy which allows quantification of mitochondrial membrane potential. $\mathrm{RH} 30$ and $\mathrm{C} 2 \mathrm{C} 12$ cells were cultured in 6-well plates $(30,000$ cells $/ \mathrm{ml})$ and treated with TMZ $(100 \mu \mathrm{M}$, $60 \mathrm{~h}$ ), Bafilomycin-A1 (Baf-A1, 4nM) and TMZ/Baf-A1.
By removing cellular growth media before staining, as well as well by washing $\mathrm{C} 2 \mathrm{C} 12 \mathrm{~s}$ with phosphate buffered saline (1×, Hyclone), but not RH30, as RH30 cells can be easily detached, staining sensitivity was increased.

TMRM (Tetramethylrhodamine Methyl Ester Perchlorate), a mitochondrial membrane dye, and Hoechst, a nuclear dye, at concentrations of $100 \mathrm{nM}$ and $10 \mu \mathrm{M}$, respectively, were diluted in media and added to cells for $30 \mathrm{~min}$ at $37^{\circ} \mathrm{C}$. Cells were imaged using an Olympus epifluorescence microscope. Fluorescence intensity was measured with ImageJ (NIH, Bethesda, MD, USA), minimum of 20 cells per condition. In each condition, fluorescence intensity for 20 cells (one by one) randomly was measured, and then intensity was averaged out for 20 cells and quantified ${ }^{82}$.

\section{Transmission electron microscopy (TEM)}

TEM was used to evaluate autophagy activation in both cell lines following treatment with TMZ or Baf-A1 or combination. TEM imaging was performed according to a protocol described previously ${ }^{21}$. Briefly, RH30 and C2C12 cells were seeded in $100 \mathrm{~mm}$ plates (300,000 cells/dish) in RPMI and DMEM (high glucose) media, respectively, supplemented with $10 \%$ FBS. Cells were treated with TMZ and Baf-A1 and then collected using EDTA for cell detachment. Cells were centrifuged three times $(1500 \times g)$ and then fixed (3\% glutaraldehyde in PBS, $\mathrm{pH} 7.4)$ for $3 \mathrm{~h}$ at room temperature. Additionally, cells were treated with a post-fixation step using $1 \%$ osmium tetroxide in phosphate buffer for $2 \mathrm{~h}$ at room temperature, followed by an alcohol dehydration series, before embedding in Epon. TEM was performed with a Philips CM10, at $80 \mathrm{kV}$, on ultra-thin sections (100 nm on 200 mesh grids) $72 \mathrm{~h}$ after treatment. Cells were stained with uranyl acetate and counterstained with lead citrate for $3 \mathrm{~min}$ sequentially. Finally, grids were washed with water for $1 \mathrm{~min}$ and dried utterly to be ready for imaging. TEM was done to confirm the autophagy induction by TMZ and autophagy suppression by Baf-A1 in the cells.

\section{Three-dimensional (3D) culture \\ Fabrication of cell-loaded collagen disks}

Disks of collagen with $5 \mathrm{~mm}$ diameter and $1 \mathrm{~mm}$ thickness loaded with 2 million cells $/ \mathrm{mL}$ were used to perform 3D culture. The disks were made by curing the suspension of cells in collagen in PDMS holders placed in 12-well plates. To fabricate the PDMS holders, the base PDMS elastomer and the curing agent were mixed with a ratio of $10 / 1$ and degassed using a vacuum chamber. The solution was then poured on a microscope slide and cured on a hot plate at $70^{\circ} \mathrm{C}$ for $2 \mathrm{~h}$ to form a uniform $1 \mathrm{~mm}$ layer. The PDMS film was then cut to $15 \mathrm{~mm}$ square 
pieces, and a $5 \mathrm{~mm}$ hole was punched through them using a biopsy punch. To sterilize the PDMS holders, they were incubated in pure ethanol for $1 \mathrm{~h}$ and baked at $80^{\circ} \mathrm{C}$ for 4 $\mathrm{h}$ to remove the ethanol. The PDMS holders were then placed in 12-well plates.

\section{RH3O and C2C12 culturing in $3 \mathrm{D}$}

RH30 and $\mathrm{C} 2 \mathrm{C} 12$ cells were cultured in a T75 culture flask in a $5 \% \mathrm{CO}_{2}$ incubator at $37^{\circ} \mathrm{C}$, supplied with culture media (DMEM with 10\% FBS and 0.5\% Pen-Strep). The media was replaced every $24 \mathrm{~h}$ and the cells were collected at a confluency of $80 \%$. To harvest cells, media were removed and cells were rinsed once with $4 \mathrm{~mL}$ of trypsinEDTA, followed by $5 \mathrm{~mL}$ of trypsin-EDTA incubation for $5 \mathrm{~min}$. Ten mililiters of media were added to the cell suspension and centrifuged at $200 \times g$ for $5 \mathrm{~min}$ at $4{ }^{\circ} \mathrm{C}$. The supernatant was removed, and the cells were resuspended in fresh media and gently mixed with collagen at $4{ }^{\circ} \mathrm{C}$ to reach a final collagen concentration of $3 \mathrm{mg} / \mathrm{mL}$ and the cell density of 2 million cells $/ \mathrm{mL}$. Twenty microliters of the solution was added to each well in the PDMS holder and placed in the incubator for $45 \mathrm{~min}$ to cure the collagen. Then $2 \mathrm{~mL}$ of media was added to each well, and the cells were cultured overnight. Treatments were started after the incubation overnight. Two conditions were considered for the study which includes control (media) and TMZ (0, 100, 250, and $500 \mu \mathrm{M})$ treatment. The cells were treated for a total of 48,72 , and $96 \mathrm{~h}$ and then the viability and immunocytochemistry were performed. All experiments were performed in triplicates.

\section{Live dead assay in $3 D$ culture}

Live/dead solution was prepared as per supplier's protocol, where $5 \mu \mathrm{L}$ of calcein $\mathrm{AM}$ and $20 \mu \mathrm{L}$ of ethidium homodimer-1 were added to $10 \mathrm{~mL}$ of DPBS. After treatment, media were removed from the wells and live/ dead solution was added followed by $2 \mathrm{~h}$ incubation at room temperature in the dark. Next, the solution was removed, and the wells were gently rinsed with DPBS twice. Confocal microscopy was performed right after the samples were stained. For quantifying viability, an image of each test case was considered to count the number of live and dead cells. The viability was quantified based on the ratio of the number of live cells to the total number of cells in each image.

\section{D immunocytochemistry}

Cells were fixed using 3.7\% formaldehyde in DPBS, after removing media, for $40 \mathrm{~min}$ at room temperature. Next, the formaldehyde solution was removed, and the samples were washed with DPBS three times for $5 \mathrm{~min}$ each. Samples were then blocked using a solution of 5\% BSA in DPBS with $0.3 \%$ Triton for $2 \mathrm{~h}$ at room temperature.
Primary antibodies were diluted in DPBS with $1 \%$ BSA and $0.3 \%$ Triton, in a dilution factor of $1 / 300$. The blocking solution was removed, and the primary antibody solutions were added to the samples and incubated overnight at $4{ }^{\circ} \mathrm{C}$. LC3 and p62 were incubated simultaneously for co-staining and PARP were incubated separately. Next day, primary antibody solutions were removed, and samples were washed three times using DPBS for $5 \mathrm{~min}$ each. The secondary antibody solutions were made by diluting the secondary antibody in DPBS with $1 \%$ BSA and $0.3 \%$ Triton with a ratio of $1 / 300$. Secondary antibodies were added to the samples and incubated for $2 \mathrm{~h}$ at room temperature in the dark. Secondary antibodies were later removed, and the solution of DAPI was added to the samples and incubated for $1 \mathrm{~h}$ at room temperature in the dark. Finally, DAPI solution was removed, and the samples were washed three times with DPBS for $5 \mathrm{~min}$ each. Confocal microscopy was performed right after the samples were stained.

\section{Statistical analysis}

All results were presented as mean $\pm \mathrm{SD}$, and the differences between the groups were tested by one-way ANOVA or two-way ANOVA analysis (non-parametric, Brown-Forsythe test), using GraphPad Prism 7.0. The confidence interval in each analysis was $95 \%$, and $P<0.05$ was considered statistically significant.

\begin{abstract}
Acknowledgements
This work was supported by a Children's Hospital Research Institute of Manitoba (CHRIM) operating grant and the University of Manitoba Collaborative Research Program to S.G. and J.W.G. Research Manitoba (RM) New Investigator operating grant also supported S.G. J.W.G. is supported by an NSERC Discovery grant. J.A. was supported by a RM studentship grant and NIMAD operating grant. J.F. is supported by studentships from NSERC and RM/ CHRIM, and S.C.d.S.R. is supported by studentships from the University of Manitoba and RM/CHRIM. P.K. is supported by an NSERC summer studentship. M.A., and E.S. thank NSERC (Discovery program) and BC Cancer Foundation for their financial support. M.A. also thanks Canadian Foundation for Innovations and B.C. Knowledge Development Fund for supporting this project.
\end{abstract}

\section{Author details}

'Department of Human Anatomy and Cell Science, Max Rady College of Medicine, Rady Faculty of Health Science, University of Manitoba, Winnipeg, Canada. ${ }^{2}$ Laboratory for Innovations in Microengineering (LiME), Department of Mechanical Engineering, University of Victoria, Victoria, BC, Canada. ${ }^{3}$ Health Policy Research Centre, Shiraz University of Medical Sciences, Shiraz, Iran. ${ }^{4}$ Colleges of Medicine and Nursing, Rady Faculty of Health Science, University of Manitoba, Winnipeg, Canada. ${ }^{5}$ Center for Biomedical Research, University of Victoria, Victoria, Canada; Center for Advanced Materials and Related

Technology (CAMTEC), University of Victoria, Victoria, Canada. ${ }^{6}$ The Biology of Breathing Theme, Children's Hospital Research Institute of Manitoba, University of Manitoba, Winnipeg, Canada. 7 The Diabetes Research Envisioned and Accomplished in Manitoba (DREAM) Theme, Children's Hospital Research Institute of Manitoba, University of Manitoba, Winnipeg, Canada

Conflict of interest

The authors declare that they have no conflict of interest. 


\section{Publisher's note}

Springer Nature remains neutral with regard to jurisdictional claims in

published maps and institutional affiliations.

Received: 11 August 2018 Revised: 20 September 2018 Accepted: 26 September 2018

Published online: 25 October 2018

\section{References}

1. Rudzinski, E. R. Histology and fusion status in rhabdomyosarcoma. (American Society of Clinical Oncology, USA). 2013

2. Goldblum, J. R., Weiss, S. W. \& Folpe, A. L. Enzinger and Weiss's Soft Tissue Tumors E-Book. (Elsevier Health Sciences, Netherland 2013).

3. Pizzo, P. A. \& Poplack, D. G. Principles and practice of pediatric oncology. (Lippincott Williams \& Wilkins, U.S.A. 2015).

4. Kashi, V. P., Hatley, M. E. \& Galindo, R. L. Probing for a deeper understanding of rhabdomyosarcoma: insights from complementary model systems. Nat. Rev. Cancer 15, 426-439 (2015).

5. Fletcher, C. D. \& Organization, W. H. WHO classification of tumours of soft tissue and bone: [this book reflects the views of a working group that convened for a consensus and editorial meeting at the University of Zurich, Switzerland, 18-20, 2012]. (Internat. Agency for Research on Cancer, U.S.A 2013).

6. Emami, A., Sepehri, Z., Gordon, J. W. \& Ghavami, S. Biologic and clinical aspects of Rhabdomyosarcoma. Int J. Basic Sci. Med 2, 1-4 (2017).

7. Mixon, B. A., Eckrich, M. J., Lowas, S. \& Engel, M. E. Vincristine, irinotecan, and temozolomide for treatment of relapsed alveolar rhabdomyosarcoma. J. Pediatr. Hematol/Oncol. 35, e163-e166 (2013).

8. Lok, B. H. et al. PARP inhibitor activity correlates with SLFN11 expression and demonstrates synergy with temozolomide in small cell lung cancer. Clin. Cancer Res. 23, 523-535 (2017).

9. Schwartz, S. et al. P-272 Selecting patients with metastatic colorectal cancer for treatment with temozolomide using proteomic analysis of MGMT. Ann. Oncol. 28, p272 (2017).

10. Gay, C. M., de Groot, P. M., Pietanza, M. C. \& Byers, L. A. Durable, exceptional response to temozolomide in a patient with extensive-stage small cell lung cancer (ES-SCLC) metastatic to brain. Cancer Treat. Res. Commun. 10, 17-20 (2017).

11. Wesolowski, J., Rajdev, P. \& Mukherji, S. Temozolomide (Temodar). Am. J. Neuroradiol. 31, 1383-1384 (2010).

12. Middleton, M. R. et al. Randomized phase III study of temozolomide versus dacarbazine in the treatment of patients with advanced metastatic malignant melanoma. J. Clin. Oncol. 18, 158-158 (2000).

13. Rosenfeld, M. R. et al. A phase $1 / / 1$ trial of hydroxychloroquine in conjunction with radiation therapy and concurrent and adjuvant temozolomide in patients with newly diagnosed glioblastoma multiforme. Autophagy $\mathbf{1 0}$ 1359-1368 (2014).

14. Esteller, M. \& Herman, J. G. Generating mutations but providing chemosensitivity: the role of O6-methylguanine DNA methyltransferase in human cancer. Oncogene 23, 1-8 (2004).

15. Pietanza, M. C. et al. Phase II trial of temozolomide in patients with relapsed sensitive or refractory small cell lung cancer, with assessment of methylguanine-DNA methyltransferase as a potential biomarker. Clin. Cancer Res. 18, 1138-1145 (2012).

16. Mojas, N., Lopes, M. \& Jiricny, J. Mismatch repair-dependent processing of methylation damage gives rise to persistent single-stranded gaps in newly replicated DNA. Genes Dev. 21, 3342-3355 (2007).

17. Cejka, P. et al. Methylation-induced G2/M arrest requires a full complement of the mismatch repair protein hMLH1. EMBO J. 22, 2245-2254 (2003).

18. Stojic, L., Brun, R. \& Jiricny, J. Mismatch repair and DNA damage signalling. DNA Repair 3, 1091-1101 (2004).

19. Klionsky, D. J. et al. Guidelines for the use and interpretation of assays for monitoring autophagy (3rd edition). Autophagy 12, 1-222 (2016).

20. Glick, D., Barth, S. \& Macleod, K. F. Autophagy: cellular and molecular mechanisms. J. Pathol. 221, 3-12 (2010).

21. Alizadeh, J. et al. Autophagy modulates transforming growth factor beta 1 induced epithelial to mesenchymal transition in non-small cell lung cancer cells. Biochim. Et. Biophys. Acta 1865, 749-768 (2018).
22. Hombach-Klonisch, S. et al. Glioblastoma and chemoresistance to alkylating agents: involvement of apoptosis, autophagy, and unfolded protein response. Pharmacol. Ther. 184, 13-41 (2018).

23. Mokarram, P. et al. New frontiers in the treatment of colorectal cancer: autophagy and the unfolded protein response as promising targets. Autophagy (2017) In press.

24. Liu, W. et al. SGK1 inhibition-induced autophagy impairs prostate cancer metastasis by reversing EMT. J. Exp. Clin. Cancer Res 37, 73 (2018).

25. Araki, M. \& Motojima, K. Hydrophobic statins induce autophagy in cultured human rhabdomyosarcoma cells. Biochem. Biophys. Res. Commun. 367, 462-467 (2008).

26. Zhou, H. et al. Ciclopirox induces autophagy through reactive oxygen speciesmediated activation of JNK signaling pathway. Oncotarget 5, 10140-10150 (2014).

27. Peron, M., Bonvini, P. \& Rosolen, A. Effect of inhibition of the ubiquitinproteasome system and Hsp90 on growth and survival of Rhabdomyosarcoma cells in vitro. BMC Cancer 12, 233 (2012).

28. Hombach-Klonisch, S. et al. Glioblastoma and chemoresistance to alkylating agents: involvement of apoptosis, autophagy, and unfolded protein response. Pharmacol. Ther. 184:13-41 (2018).

29. Mukhopadhyay, S., Panda, P. K., Sinha, N., Das, D. N. \& Bhutia, S. K. Autophagy and apoptosis: where do they meet? Apoptosis 19, 555-566 (2014).

30. Mariño, G., Niso-Santano, M., Baehrecke, E. H. \& Kroemer, G. Self-consumption: the interplay of autophagy and apoptosis. Nat. Rev. Mol. Cell Biol. 15, 81-94 (2014).

31. Ghavami, S. et al. Geranylgeranyl transferase 1 modulates autophagy and apoptosis in human airway smooth muscle. Am. J. Physiol.-Lung Cell Mol. Physiol. 302, L420-L428 (2012).

32. Ghavami, S. et al. Apoptosis, autophagy and ER stress in mevalonate cascade inhibition-induced cell death of human atrial fibroblasts. Cell Death Dis. 3, e330 (2012).

33. Shimizu, S. et al. Role of BCl-2 family proteins in a non-apoptotic programmed cell death dependent on autophagy genes. Nat. Cell Biol. 6, 1221-1228 (2004).

34. $\mathrm{Yu}$, L. et al. Regulation of an ATG7-beclin 1 program of autophagic cell death by caspase-8. Science 304, 1500-1502 (2004).

35. Ghavami, S. et al. Mevalonate cascade regulation of airway mesenchymal cell autophagy and apoptosis: a dual role for p53. PLOS ONE 6, e16523 (2011).

36. Ghavami, S. et al. Airway mesenchymal cell death by mevalonate cascade inhibition: integration of autophagy, unfolded protein response and apoptosis focusing on Bcl2 family proteins. Biochim. Et. Biophys. Acta 1843, 1259-1271 (2014).

37. Ghavami, S. et al. S100A8/A9 induces autophagy and apoptosis via ROSmediated cross-talk between mitochondria and lysosomes that involves BNIP3. Cell Res. 20, 314-331 (2010).

38. Mughal, W. et al. Myocardin regulates mitochondrial calcium homeostasis and prevents permeability transition. Cell Death Differ. https://doi.org/10.1038/ s41418-018-0073-z (2018).

39. Mughal, W. et al. A conserved MADS-box phosphorylation motif regulates differentiation and mitochondrial function in skeletal, cardiac, and smooth muscle cells. Cell Death Dis. 6, e1944 (2015).

40. Goldstein, J. C., Waterhouse, N. J., Juin, P., Evan, G. I. \& Green, D. R. The coordinate release of cytochrome $c$ during apoptosis is rapid, complete and kinetically invariant. Nat. Cell Biol. 2, 156-162 (2000).

41. Zeglinski, M. R. et al. Chronic expression of Ski induces apoptosis and represses autophagy in cardiac myofibroblasts. Biochim. Et. Biophys. Acta 1863, 1261-1268 (2016).

42. Chaabane, W. et al. Human-gyrovirus-Apoptin triggers mitochondrial death pathway--Nur77 is required for apoptosis triggering. Neoplasia 16, 679-693 (2014).

43. Chaabane, W., Ghavami, S., Malecki, A. \& Los, M. J. Human gyrovirus-apoptin interferes with the cell cycle and induces G2/M arrest prior to apoptosis. Arch. Immunol. Ther. Exp. 65, 545-552 (2017).

44. Ghavami, S. et al. Apoptosis and cancer: mutations within caspase genes. J. Med Genet 46, 497-510 (2009).

45. Hsu, S. P. C. et al. Temozolomide, sirolimus and chloroquine is a new therapeutic combination that synergizes to disrupt lysosomal function and cholesterol homeostasis in GBM cells. Oncotarget 9, 6883-6896 (2018).

46. Yamamoto, Y. et al. Intracellular cholesterol level regulates sensitivity of glioblastoma cells against temozolomide-induced cell death by modulation of caspase- 8 activation via death receptor 5 -accumulation and activation in the 
plasma membrane lipid raft. Biochem Biophys. Res. Commun. 495, 1292-1299 (2018).

47. Zhang, P. et al. Rutin increases the cytotoxicity of temozolomide in glioblastoma via autophagy inhibition. J. Neurooncol 132, 393-400 (2017).

48. Klionsky, D. J., Elazar, Z., Seglen, P. O. \& Rubinsztein, D. C. Does bafilomycin A1 block the fusion of autophagosomes with lysosomes? Autophagy. 4, 849-50 (Taylor \& Francis, 2008).

49. Yeganeh, B. et al. Suppression of influenza A virus replication in human lung epithelial cells by noncytotoxic concentrations bafilomycin A1. Am. J. Physiol. Lung Cell Mol. Physiol. 308, L270-L286 (2015).

50. Yeganeh, B. et al. Autophagy activation is required for influenza A virusinduced apoptosis and replication. Biochim. Et. Biophys. Acta 1865, 364-378 (2018).

51. Valente, K. P. et al. Microfluidic technologies for anticancer drug studies. Drug Discov. Today 22, 1654-1670 (2017).

52. Pedde, R. D. et al. Emerging biofabrication strategies for engineering complex tissue constructs. Adv. Mater. https://doi.org/10.1002/adma.201606061 29 (2017).

53. Board, P. P. T. E. Childhood Rhabdomyosarcoma Treatment (PDQ $\left.{ }^{\circledR}\right)$. (2017). https://www.cigna.com/individuals-families/health-wellness/hw/medicaltopics/childhood-rhabdomyosarcoma-treatment-ncicdr0000062792

54. Wagner, L. M. et al. Phase I trial of temozolomide and protracted irinotecan in pediatric patients with refractory solid tumors. Clin. Cancer Res. 10, 840-848 (2004).

55. Houghton, P. J. et al. Antitumor activity of temozolomide combined with irinotecan is partly independent of O6-methylguanine-DNA methyltransferase and mismatch repair phenotypes in xenograft models. Clin. Cancer Res. 6 , 4110-4118 (2000).

56. Kushner, B. H., Kramer, K., Modak, S. \& Cheung, N.-K. V. Irinotecan plus temozolomide for relapsed or refractory neuroblastoma. J. Clin. Oncol. 24, 5271-5276 (2006).

57. Wagner, L. M. et al. Temozolomide and intravenous irinotecan for treatment of advanced Ewing sarcoma. Pediatr. Blood Cancer 48, 132-139 (2007).

58. Mathew, R., Karantza-Wadsworth, V. \& White, E. Role of autophagy in cancer. Nat. Rev. Cancer 7, 961-967 (2007).

59. Hou, Y.-J. et al. Inhibition of active autophagy induces apoptosis and increases chemosensitivity in cholangiocarcinoma. Lab. Investig. 91, 1146-1157 (2011).

60. Janku, F., McConkey, D. J., Hong, D. S. \& Kurzrock, R. Autophagy as a target for anticancer therapy. Nat. Rev. Clin. Oncol. 8, 528-539 (2011).

61. Gump, J. M. \& Thorburn, A. Autophagy and apoptosis: what is the connection? Trends Cell Biol. 21, 387-392 (2011).

62. Ghavami, S. et al. Autophagy regulates trans fatty acid-mediated apoptosis in primary cardiac myofibroblasts. Biochim. Et. Biophys. Acta 1823, 2274-2286 (2012).

63. Hare, B. D. et al. Two weeks of variable stress increases gamma-H2AX levels in the mouse bed nucleus of the stria terminalis. Neuroscience (2018).

64. Ji, J. et al. Phosphorylated fraction of H2AX as a measurement for DNA damage in cancer cells and potential applications of a novel assay. PLOS ONE 12, e0171582 (2017).

65. D'Atri, S. et al. Involvement of the mismatch repair system in temozolomideinduced apoptosis. Mol. Pharmacol. 54, 334-341 (1998).

66. Ensign, S. P. F. et al. SGEF is regulated via TWEAK/Fn14/NF-KB signaling and promotes survival by modulation of the DNA repair response to temozolomide. Mol. Cancer Res. 14, 302-312 (2016).

67. Roos, W. P. \& Kaina, B. DNA damage-induced cell death by apoptosis. Trends Mol. Med. 12, 440-450 (2006).

68. Zhang, X., Ni, Q., Wang, Y., Fan, H. W. \& Li, Y. Synergistic anticancer effects of formononetin and temozolomide on glioma C6 cells. Biol. Pharm. Bull. https:// doi.org/10.1248/bpb.b18-00002 (2018).

69. Rao, J. U. et al. Temozolomide arrests glioma growth and normalizes intratumoral extracellular pH. Sci. Rep. 7, 7865 (2017).

70. Jakubowicz-Gil, J. et al. Temozolomide and sorafenib as programmed cell death inducers of human glioma cells. Pharmacol. Rep. 69, 779-787 (2017).
71. Liu, J. et al. Bufalin induces apoptosis and improves the sensitivity of human glioma stem-like cells to temozolamide. Oncol. Res., https://doi.org/10.3727/ 096504018 X15270916676926 (2018).

72. Weatherbee, J. L., Kraus, J. L. \& Ross, A. H. ER stress in temozolomide-treated glioblastomas interferes with DNA repair and induces apoptosis. Oncotarget 7, 43820-43834 (2016)

73. Martinou, J.-C. \& Youle, R. J. Mitochondria in apoptosis: Bcl-2 family members and mitochondrial dynamics. Dev. Cell 21, 92-101 (2011).

74. Hata, A. N., Engelman, J. A. \& Faber, A. C. The BCL2 family: key mediators of the apoptotic response to targeted anticancer therapeutics. Cancer Discov. 5 475-487 (2015).

75. Rashedi, I., Panigrahi, S., Ezzati, P., Ghavami, S. \& Los, M. Autoimmunity and apoptosis--therapeutic implications. Curr. Med. Chem. 14, 3139-3151 (2007).

76. Baig, S. et al. Potential of apoptotic pathway-targeted cancer therapeutic research: Where do we stand? Cell Death Dis. 7, e2058 (2017).

77. Vidal, S., Rodriguez-Bravo, V., Galsky, M., Cordon-Cardo, C. \& DomingoDomenech, J. Targeting cancer stem cells to suppress acquired chemotherapy resistance. Oncogene 33, 4451 (2014).

78. Velpula, K. K. et al. Metabolic targeting of EGFRvIII/PDK1 axis in temozolomide resistant glioblastoma. Oncotarget 8, 35639-35655 (2017).

79. Nanegrungsunk, D. et al. Bevacizumab is superior to Temozolomide in causing mitochondrial dysfunction in human brain tumors. Neurol. Res $\mathbf{3 8}, 285-293$ (2016).

80. Friedrich, J., Ebner, R. \& Kunz-Schughart, L. A. Experimental anti-tumor therapy in 3-D: spheroids--old hat or new challenge? Int. J. Radiat. Biol. 83, 849-871 (2007).

81. Padron, J. M. et al. The multilayered postconfluent cell culture as a model for drug screening. Crit. Rev. Oncol. Hematol. 36, 141-157 (2000).

82. Alizadeh, J. et al. Mevalonate cascade inhibition by simvastatin induces the intrinsic apoptosis pathway via depletion of isoprenoids in tumor cells. Sci. Rep. 7, 44841 (2017)

83. Thanasupawat, $T$. et al. Platinum (IV) coiled coil nanotubes selectively kill human glioblastoma cells. Nanomedicine 11, 913-925 (2015)

84. Thanasupawat, T. et al. Dovitinib enhances temozolomide efficacy in glioblastoma cells. Mol. Oncol. 11, 1078-1098 (2017).

85. Ghavami, S. et al. Brevinin-2R1 semi-selectively kills cancer cells by a distinct mechanism, which involves the lysosomal-mitochondrial death pathway. J. Cell Mol. Med. 12, 1005-1022 (2008).

86. Hashemi, M., Ghavami, S., Eshraghi, M., Booy, E. P. \& Los, M. Cytotoxic effects of intra and extracellular zinc chelation on human breast cancer cells. Eur. J. Pharmacol. 557, 9-19 (2007).

87. Riccardi, C. \& Nicoletti, I. Analysis of apoptosis by propidium iodide staining and flow cytometry. Nat. Protoc. 1, 1458-1461 (2006).

88. Kabeya, Y. et al. LC3, a mammalian homologue of yeast Apg8p, is localized in autophagosome membranes after processing. EMBO J. 19, 5720-5728 (2000).

89. Mizushima, N. Methods for monitoring autophagy. Int. J. Biochem. Cell Biol. 36 2491-2502 (2004)

90. Kimura, S., Noda, T. \& Yoshimori, T. Dissection of the autophagosome maturation process by a novel reporter protein, tandem fluorescent-tagged LC3. Autophagy 3, 452-460 (2007).

91. Ni, H.-M. et al. Dissecting the dynamic turnover of GFP-LC3 in the autolysosome. Autophagy 7, 188-204 (2011).

92. Moosavi, M. A. et al. Photodynamic $\mathrm{N}-\mathrm{TiO}_{2}$ nanoparticle treatment induces controlled ROS-mediated autophagy and terminal differentiation of leukemia cells. Sci. Rep. 6, 34413 (2016).

93. Distelmaier, $F$. et al. Life cell quantification of mitochondrial membrane potential at the single organelle level. Cytom. Part A J. Int. Soc. Anal. Cytol. 73, 129-138 (2008).

94. Floryk, D. \& Houstek, J. Tetramethyl rhodamine methyl ester (TMRM) is suitable for cytofluorometric measurements of mitochondrial membrane potential in cells treated with digitonin. Biosci. Rep. 19, 27-34 (1999). 